\title{
CONFLUENCIA EN TORNO AL PRINCIPIO DE PUERTAS ABIERTAS. ESPECIAL REFERENCIA A LAS MODIFICACIONES LEGISLATIVAS RECIENTES EN EL ORDENAMIENTO ESPAÑOL
}

\author{
Rufino Benítez García \\ Doctorando en Derecho \\ Universidad de Sevilla \\ https://orcid.org/0000-0002-9544-8224
}

\section{RESUMEN}

El objeto de reflexión es el principio cooperativo de adhesión voluntaria y abierta, seña de identidad y verdadero condicionante para la cooperación, en tanto que principio consolidado en la Declaración de la Alianza Cooperativa Internacional (ACI) sobre Identidad Cooperati$v a$ (Manchester, 1995), y que configura un sistema accesible a todas las personas que se muestren dispuestas a participar en la cooperativa. Dicho principio ético posee un carácter informador de la cooperativa, cuya permanencia desde Rochdale hasta actualidad ha sido incuestionada, y nuestro objetivo será resaltar las más recientes modificaciones en el Derecho cooperativo autonómico en relación con este principio. En este mosaico legislativo hay puntos de confluencia, materializándose la reclamada armonización en el respeto a dichos principios configuradores, sin que la autonomía organizativa propia de la cooperativa se haya visto menoscabada. Se finalizará con una propuesta de posibles reformas en aras de un entendimiento razonado del principio.

PALABRAS CLAVE: Adhesión libre, baja voluntaria, principios cooperativos, puertas abiertas.

CLAVES ECONLIT / ECONLIT DESCRIPTORS: P130, K200, K220, L31.

Cómo citar este artículo/How to cite this article: BENÍTEZ GARCÍA, Rufino: "Confluencia en torno al principio de puertas abiertas. Especial referencia a las modificaciones legislativas recientes en el ordenamiento español", CIRIEC-España, Revista Jurídica de Economía Social y Cooperativa, n 38, 2021, pp. 127-167. DOI: 10.7203/CIRIEC-JUR.38.20639 


\section{CONFLUENCE AROUND THE PRINCIPLE OF ADHESION AND VOLUNTARY WITHDRAWAL. SPECIAL REFERENCE TO RECENT LEGISLATIVE MODIFICATIONS IN THE SPANISH LEGAL SYSTEM}

\section{EXPANDED ABSTRACT}

The object of reflection of this article is the cooperative principle of voluntary and open membership, identity sign and true conditioner for cooperation, as a principle consolidated in the Declaration of the International Cooperative Alliance (ICA) on Cooperative Identity (Manchester, 1995), and which configures a system accessible to all people that they are willing to participate in the cooperative, preventive of any discrimination when accepting or denying the admission of a member, and that it has found accommodation in the Spanish Constitution in art. 129.2. This Declaration reformulates the principles, specifically, regarding voluntary and open membership, in the sense that cooperatives are "voluntary organizations, open to all people capable of using their services and willing to accept their responsibilities as a member, without social, political, religious, racial or sex discrimination". Therefore, prohibiting transactions with non-member third parties would hinder their expansion, as it is an impediment for them to fulfill their function, since, like all companies, they must act in the market, consequence of the progressive process of commercialization that has suffered. This ethical principle (since it delimits its personal, supportive nature and that of its members, and that may or may not find expression in the national and regional legal provisions, given its flexible nature, without having binding legal force) has an informative character on the operation of the cooperative, rising as a true interpretive element of its regulations. Indeed, as a representative entity of the social economy, it must remain faithful to the principles of cooperativism formulated by the ICA, among them, to this principle of free adherence or open doors, in the sense that there is a door to enter (positive aspect) and another to go out (negative aspect). This postulate is conceived as the first cooperative principle, by which third parties have a free hand to enter the corporate sphere at any time to satisfy their needs as partners, having overcome the paradigm that cooperatives should only operate with their own associates.

From the opposite point of view, the power to freely unsubscribe is based on the full voluntariness of the condition of cooperative person, and no one can be obliged to remain in that society. In this sense, we position ourselves in favor of a cooperative model far from past restrictions, and in accordance with the principle of free enterprise enshrined in article 38 of the Constitution, the fundamental core of the system. 
This principle is the most powerful, as a manifestation of cooperative altruism, by wanting all its members to benefit from the advantages of cooperation, thus fulfilling their social function. Its permanence from Rochdale (origin of modern cooperativism) to the present has been unquestioned. The purpose of the writing will be to highlight the most recent modifications in autonomous cooperative law in relation to this open-door principle, because their legal significance is subject to the terms in which they have been incorporated into the respective internal laws. However, it is not possible to take this consideration to its ultimate consequences, observing them as immutable rules, but as guidelines for action, because the principle formally considered is not standardized. Meanwhile, these principles will remain in an ethical sphere, without finding legal expression. We must question whether there is an alleged subjective right to entry, or, at least, that the applicant is the holder of a legitimate interest to join the cooperative. Question that, as we will see in our text, does not find a unanimous answer from the conglomerate of rules of the Spanish legal system. In any case, and as a general rule, we can affirm that there is no right, by which an applicant can, by their own will, adhere to society. On the contrary, it is at the discretion of the cooperative the admission of a person who, complying with the requirements, expresses his desire to join, because the personalist nature of these collective formations prevails.

This doctrine has been legislatively reflected in the vast majority of regional laws. We are prone, therefore, to claim a unity of legal regime, undisputed in the rest of social forms, and a minimum legislative harmonization. In any case, the majority of cooperative autonomous texts find consensus around the relevance acquired by the cooperative principles established by the ICA. In this legislative mosaic there are points of confluence, materializing the demanded harmonization in respect of said universal configuring principles, without the organizational autonomy of the cooperative having been impaired.

Very important has been the approval of the Basque Cooperatives Law in 2019, whose art. 47.1 orders respect for cooperative principles between the duties of administrators, and its art. 117.4 a) that the "distortion of the cooperative is considered a very serious offense, when the cooperative principles recognized in this law are repeatedly violated or when persons who cannot legally be members are admitted as partners". In fact, its art. 20, entitled "right to admission", establishes that, "(...) any person who meets the requirements of the previous article (referring to people who may be members) and is interested in using the services of the cooperative, has the right to to join as a member unless a just cause derived from the activity or corporate purpose of the cooperative prevents it". It should be noted the exception that supposes the existence of a just cause, restricting the operation of the principle of open doors, a true limit for the aspiring member, despite compliance with the requirements set by art. 19 of said Law. Although, there is no discretion on the part of the cooperative for this rejection, since the just cause must derive from its activity or corporate 
purpose, and must be objective, and its qualification cannot be left to the discretion of the Governing Council.

We will end with a discussion of possible reforms that should be carried out in order to find a reasoned understanding of the principle. It seems essential to us to reconcile the adaptation of cooperatives to new business demands with the maintenance of their identity, which is threatened by the legislative profusion of the national cooperative order.

KEYWORDS: Voluntary membership, voluntary withdrawal, cooperative principles, open doors. 


\section{SUMARIO}

I. Introducción. II. La adhesión voluntaria y el principio de puertas abiertas en la sociedad cooperativa española: aspectos fundamentales para su comprensión. 1. Aspectos preliminares. La Cooperativa como empresa abierta. 2. La adhesión y baja voluntaria como valor y principio ético. 3. Plasmación del principio en las normas jurídicas. III. Tratamiento del principio por la Alianza Cooperativa Internacional (ACI). 1. Consideraciones introductorias. 2. La Declaración de la ACI sobre Identidad Cooperativa (Manchester, 1995). Posición de la Alianza sobre este principio. IV. Recepción del principio por el ordenamiento cooperativo español y su necesaria armonización. 1. La especial configuración del Derecho cooperativo en España: la dispersión normativa como rasgo característico. 2. Situación normativa estatal vigente: La Ley 27/1999, de 16 de julio, de Cooperativas. 3. Las leyes autonómicas de sociedades cooperativas. V. Modificaciones legislativas recientes en las CC.AA. El objetivo de la necesaria armonización normativa en torno a este principio. 1. Análisis de las novedades relativas a este principio. 2. Perspectivas de ulteriores reformas en la legislación estatal y autonómica en lo atinente a este principio, en aras de su armonización. VI. Conclusiones. Bibliografía.

\section{Introducción}

La sociedad cooperativa, en cuanto que forma de organización de una serie de personas que se alían al objeto de satisfacer necesidades o aspiraciones comunes, responde a un instinto natural de ayuda mutua. Y si hay algún factor que distingue a la cooperativa de las sociedades capitalistas es que la entrada de un socio en la primera tiene lugar a través de un proceso más complejo que el preciso para devenir accionista. En este sentido, la adquisición de acciones confiere la condición de accionista de la anónima, al contrario que cuando un aspirante pretende hacerse partícipe de una cooperativa, por cuanto que la persona socia ha de ser aceptada por el Consejo Rector.

En sede específica de cooperativas, el principio básico de "adhesión voluntaria y libre" o "puertas abiertas" impide toda discriminación en la admisión de un socio/a, y se sustenta en el paradigma de que cuantas más personas se adhieran a la sociedad, con mayor facilidad se alcanzarían los objetivos sociales. Por ejemplo, en el caso de las cooperativas de trabajo asociado (CTA), ello nos lleva a entender que cuando la naturaleza del objeto social precisa la observancia de ciertas aptitudes o habilidades en los sujetos que deban realizar la actividad cooperativa, dichas capacidades han de estar predeterminadas. 
Como se observará, este principio (como el resto de principios cooperativos) se consolida con ocasión de la Declaración de la Alianza Cooperativa Internacional (ACI) sobre Identidad Cooperativa (Manchester, 1995), alzándose en verdadero elemento interpretativo de la normativa cooperativa, dado su carácter informador del funcionamiento de estas entidades, y que ha hallado acomodo en nuestra Constitución (CE) en el art. 129.2. Sin embargo, al carecer de fuerza jurídica vinculante, su eficacia estará condicionada a su plasmación en las disposiciones jurídicas nacional y autonómicas. Se procederá, en este sentido, a analizar si, a pesar de la existencia en Espańa de un auténtico ordenamiento plurilegislativo, se dan los oportunos puntos de confluencia que puedan llevar a la ansiada armonización del ordenamiento cooperativo español en torno a este principio básico formulado por la ACI. A este respecto, se estudiarán las más recientes modificaciones producidas en las leyes autonómicas cooperativas en lo atinente a este principio fundamental.

En los últimos años, las alteraciones legislativas han discurrido por una línea continuista de equilibrio entre la autonomía organizativa cooperativa y el respeto de los principios generalmente admitidos. No obstante, no han faltado leyes autonómicas que entienden que el sacralizar dichos principios supone poco menos que un lastre para el desarrollo mismo de la cooperativa, al desvirtuarse sus rasgos propios y perder su singularidad respecto de los entes capitalistas.

\section{La adhesión voluntaria y el principio de puertas abiertas en la sociedad cooperativa espańola: aspectos fundamentales para su comprensión}

\section{Aspectos preliminares. La Cooperativa como empresa abierta}

La cooperativa, buque insignia de la economía social, es una empresa abierta, dada la variabilidad de su capital y a que el número de sus potenciales integrantes es ilimitado, operando a través de una empresa de propiedad conjunta y gestión democrática, cuyos rasgos distintivos deben analizarse atendiendo a su fin mutualista ${ }^{1}$. Su funcionamiento interno, sin embargo, está impregnado de principios de auténtica democracia económica (art. $38 \mathrm{CE}$ ), y de un cierto componente lucrativo, compatible con su específica función social y con los tradicionales principios generales de

1. Principio, el mutualista, que, como vino a disponer la Sentencia del Tribunal Supremo (en lo sucesivo, STS) de 3 de julio de 2018, informa tanto la legislación cooperativa estatal como autonómica. 
la cooperación ${ }^{2}$. Por consiguiente, prohibir las transacciones con terceros no socios obstaculizaría su expansión, al suponer un impedimento para la función que le es propia, ya que, como toda empresa, deben actuar en el mercado. En consecuencia, la admisión de terceros en el desarrollo de la actividad cooperativizada queda condicionada a su previsión estatutaria ${ }^{3}$.

De esta manera, la mutualidad, en tanto que reciprocidad de prestaciones, y cuyo fin último es el beneficio de las personas socias, aunque es su concepto definitorio, no es exclusivo de esta forma social, en el sentido de no poder realizar prestaciones más que con las personas socias. Por cuanto que, la cooperativa constituye una empresa, una sociedad mercantil que produce y distribuye bienes y servicios en el mercado, sin que el ánimo de lucro resulte esencial a la misma. Este escenario no es sino consecuencia del progresivo proceso de mercantilización que ha sufrido. Recuérdese la definición de cooperativa que se observaba en la extinta Ley General de Cooperativas de 1931 (en lo siguiente, LGC de 1931) , conceptuada como "asociación de personas naturales o jurídicas que, sujetándose en su organización y en su funcionamiento a las prescripciones del presente Decreto y tendiendo a eliminar el lucro, tenga por objeto satisfacer alguna necesidad común (...)”’

Uno de sus objetivos, en tanto que empresa, es su crecimiento económico, abriéndose al mayor número de personas con las mismas necesidades. Si bien, como entidad de la economía social, debe mantenerse fiel a los principios formulados por la ACI, entre ellos, el de libre adhesión o puertas abiertas, significante de la existen-

2. Véase: LLOBREGAT HURTADO, M.L.: Mutualidad y empresas cooperativas, J. M. Bosch Editor, Barcelona, 2005, pp. 228 y ss.; MORILLAS JARILLO, M.J. \& FELIÚ REY, M.I.: Curso de Cooperativas, Editorial Tecnos, Madrid, 2019; y SERRANO Y SOLDEVILLA, A.D.: La cooperativa como sociedad abierta, Ministerio de Trabajo y Seguridad Social, Servicio de Publicaciones, Sevilla, 1982, pp. 44 y ss. En contra, sosteniendo que la cooperativa no es una sociedad y, menos aún, una sociedad mercantil, vid. VICENT CHULIÁ, F.: "Introducción. Normas y ámbito de aplicación". En: Tratado de Derecho de sociedades cooperativas (dir. PEINADO GRACIA, J.I. \& coord. VÁZQUEZ RUANO, T.), Tirant lo Blanch, València, 2019, pp. 93 y ss.

3. Vid. FAJARDO GARCÍA, I.G.: "Novedades en la Ley 27/1999, de 16 de julio, en torno a la constitución y los socios de la cooperativa", REVESCO. Revista de Estudios Cooperativos, no 69, 1999, p. 97; MONZÓN CAMPOS, J.L.: "Las cooperativas de trabajo asociado ante la reforma de los principios cooperativos", $R E$ VESCO. Revista de Estudios Cooperativos, no 61, 1995, p. 51; y SERRANO Y SOLDEVILLA, A.D., op. cit., pp. 21, 80 y 296. En la jurisprudencia, véase la relevante Sentencia del Tribunal Constitucional (STC) $72 / 1983$, de 29 de julio.

4. Promulgada el 9 de septiembre de 1931, y publicada en la Gaceta de Madrid el día 10 de septiembre del mismo año.

5. Véase, adicionalmente: GADEA SOLER, E.: "Delimitación del concepto de cooperativa: de los principios cooperativos a la responsabilidad social cooperativa”, CIRIEC-España, Revista Jurídica de Economía Social y Cooperativa, no 23, 2012, p. 7. 
cia de una puerta para entrar (aspecto positivo) y otra para salir (aspecto negativo), permitiendo el constante flujo y reflujo de personas extrańas al contrato constitutivo, que da lugar a esa variación en la cifra del capital. Este postulado se concibe como el primer principio cooperativo, por el cual, los terceros tienen vía libre para ingresar en cualquier momento en la esfera societaria para satisfacer sus necesidades como $\operatorname{socios}^{6}$.

Igualmente, la facultad de darse de baja libremente se funda en la plena voluntariedad de la condición de persona cooperativista, no pudiendo ser nadie obligado a permanecer en ella. Al tiempo que este derecho personal a causar baja no es absoluto, pudiendo ser restringido a través de los estatutos, para garantizar la estabilidad de la actividad cooperativizada, siempre que la persona socia pueda transmitir sus aportaciones sociales conforme al régimen previsto para la transmisión del capital. Por otro lado, este derecho no puede ser ejercitado si dicha persona socia está incursa en un expediente disciplinario ${ }^{7}$.

Por consiguiente, no es la mayoría de socios/as la que puede decidir sobre el inicio y la ruptura de la relación societaria de la persona cooperativista, sino que es el aspirante, si cumple los requisitos estatutarios, el que solicita su ingreso al Consejo Rector, que, salvo motivo justificado ${ }^{8}$, deberá aceptar su solicitud. Desde esta perspectiva, hay que postularse en favor de un modelo de cooperativa acorde con el principio de libertad de empresa consagrado en el artículo $38 \mathrm{CE}$, piedra angular del sistema. De esta manera, nada obsta a conceder plena validez al principio de puertas abiertas como esencial a la idea de cooperación, en tanto que mantiene su ratio de servir de medio de entrada a nuevos socios/as.

6. Bajo esta concepción, vid. PAZ CANALEJO, N.: "Principios cooperativos y prácticas societarias de la cooperación”, REVESCO. Revista de Estudios Cooperativos, no 61, 1995, p. 4; y MARTÍNEZ CHARTERINA, A.: "El principio de adhesión voluntaria y abierta desde una perspectiva histórica y doctrinal", Boletín de la Asociación Internacional de Derecho Cooperativo (BAIDC), no 51, 2017, pp. 184 y ss. DOI: http://dx.doi. org/10.18543/baidc-51-2017pp179-190.

7. Parece discrepar, por su parte, PULGAR EZQUERRA, J.: "La pérdida de la condición de socio en el marco cooperativo: baja y expulsión”. En: Estudios de Derecho Mercantil. En memoria del Profesor Aníbal Sánchez Andrés (coords. SÁENZ GARCÍA DE ALBIZU, J.C., OLEO BANET, F. \& MARTÍNEZ FLÓREZ, A.), Civitas, Pamplona, 2010, pp. 1.045 y ss.; cuando estipula que, “(...) la baja voluntaria puede producirse por cualquier causa y en cualquier tiempo, de forma que la permanencia temporal mínima asumida por el socio no conlleva una renuncia a su derecho a causar baja sino una penalización económica (...)”.

8. Vid. LASSALETTA GARCÍA, P.J.: El acceso a la condición de socio en la sociedad cooperativa de trabajo asociado, Editorial Reus, Madrid, 2011, p. 171. 


\section{La adhesión y baja voluntaria como valor y principio ético}

La Declaración sobre la Identidad Cooperativa, adoptada por la ACI en Manchester, en 1995, a la que se aludirá ampliamente infra ${ }^{9}$, reformula los llamados principios cooperativos, que ya habían estado presentes en algunas entidades que se puede considerar precedentes de la cooperativa, como la de los "Justos Pioneros de Rochdale" (Rochdale Equitable Pioneers Society), fundada el 24 de agosto de 1844.

Los valores cooperativos de autoayuda, autorresponsabilidad, democracia, igualdad, equidad y solidaridad, fundamento de dichos principios, se presentan como las concepciones de las personas cooperativistas sobre lo que es bueno, deseable y merece ser perseguido para mejorar las condiciones de vida. Todos estos valores cooperativos a los que se refiere la $\mathrm{ACI}$ son valores éticos, pues condensan las normas de comportamiento que debe llevar a cabo dicha entidad, al estar relacionados con el desarrollo personal de los seres humanos. Debe evitarse ver en ellos un mero "decálogo" que haya de cumplirse al pie de la letra, sino que constituyen unos postulados a los que ha de atenderse de modo sistemático, ya que, de modo contrario, su espíritu y finalidad se verán menoscabados ${ }^{10}$.

Los principios cooperativos de afiliación voluntaria y abierta; de control democrático de los miembros; de participación económica de estos; de autonomía e independencia; de educación, formación e información; de cooperación entre cooperativas; y de interés por la comunidad, por su parte, constituyen mandatos de optimización que ordenan que algo se realice de acuerdo con las posibilidades fácticas o jurídicas que ayudan a conformar los preceptos normativos o actitudinales, salvaguardando su esencia y espíritu ${ }^{11}$. En este sentido, a través de la cooperativa, además de conseguir los objetivos fijados por sus partícipes, se pone en alza el lado moral del individuo. En consecuencia, en la Exposición de Motivos (E.M.) de la Ley 27/1999, de 16 de julio,

9. Se alude al apdo. III.2, titulado "La Declaración de la ACI sobre Identidad Cooperativa (Manchester, 1995). Posición de la Alianza sobre este principio”.

10. Vid. MORENO FONTELA, J.L.: "Las relaciones entre los valores y principios cooperativos y los principios de la normativa cooperativa”, REVESCO. Revista de Estudios Cooperativos, no 124, 2017, p. 117. DOI: http://dx.doi.org/10.5209/REVE.54923.

11. Vid. MIRANDA, J.E. DE: "De la adhesión voluntaria a las puertas abiertas a medias: la arbitrariedad en el cumplimiento de un principio cooperativo", Boletín de la Asociación Internacional de Derecho Cooperativo (BAIDC), no 51, 2017, p. 66. DOI: https://doi.org/10.18543/baidc-51-2017pp63-77; y TRUJILLO DÍEZ, I.J.: "El valor jurídico de los principios cooperativos. A propósito de la Ley 27/1999, de 16 de julio, de cooperativas", Revista Crítica de Derecho Inmobiliario, no 658, 2000, p. 1.331. En contra, vid. SANTOS DOMÍNGUEZ, M.A.: El poder de decisión del socio en las sociedades cooperativas: la Asamblea General, Aranzadi, Cizur Menor (Navarra), 2014, p. 85. 
de Cooperativas ${ }^{12}$ (LCOOP), al disponerse que "los valores éticos que dan vida a los principios cooperativos formulados por la Alianza Cooperativa Internacional (...)", se vislumbra esta concepción ética, que no jurídica, de los mencionados principios.

En este sentido, los Congresos de la ACI de Viena (1930), París (1937), y Viena (1966), supusieron un punto de referencia en su evolución respecto de los enunciados en una primera versión por los Pioneros de Rochdale (1844), origen del "cooperativismo moderno", con un modelo definido y unas pautas de organización concretas, tomando cuerpo en el control democrático; la libre adhesión; el interés limitado al capital; los retornos de excedentes en proporción a las compras, entre otros. Aunque la ACI no se constituyó formalmente hasta 1895, los principios cooperativos fueron considerados como tales en el X Congreso en Basilea (Suiza), en 1921. Puede afirmarse, a este respecto, que los mismos no han sido formulados ex origine por el legislador, sino que son presupuestos de dicha regulación, en tanto que estructura normativa mínima que toda cooperativa debe poseer ${ }^{13}$.

Por consiguiente, el principio de adhesión voluntaria y abierta, como el resto de principios, posee un carácter informador de la cooperativa, al delimitar su naturaleza personal, solidaria y la de sus miembros, y que puede o no hallar plasmación en las disposiciones jurídicas, dado su carácter flexible, careciendo de fuerza jurídica vinculante $^{14}$. El mismo entronca con los meritados valores cooperativos de autoayuda, autorresponsabilidad y solidaridad, en el buen entender de que sólo unas entidades que estén dispuestas a asumir que quienes están fuera merecen cobertura y protección, practicarán una política de puertas abiertas, invitándolos a entrar sin trabas artificiales u onerosas.

\section{Plasmación del principio en las normas jurídicas}

Como se ha adelantado, los principios cooperativos no pueden definirse como postulados filosóficos, sino como ideas que derivan de la experiencia práctica, y su trascendencia jurídica se supedita a los términos en que hayan sido incorporados en las respectivas legislaciones internas. De esta manera, dichos principios no encierran un mandato al legislador para que regule la cooperativa conforme a los mismos, lo 
que condiciona su eficacia como criterios correctores de posibles impurezas del legislador correspondiente ${ }^{15}$.

No obstante, el mencionado carácter informador del funcionamiento de la cooperativa condiciona su régimen legal, al constituirse en fuente material de su legislación, e influir sobre su contenido, lo que les agrega una cualidad como elemento de interpretación de dicha normativa. De manera que, una regulación ajena a dichos principios impediría calificar a las sociedades como cooperativas ${ }^{16}$. En contra de este parecer, se sostiene que son las leyes y no los principios cooperativos las que configuran dicha entidad, aludiendo a la formulación empleada por la derogada Ley de Cooperativas del País Vasco de $1993^{17}$, que refería que la cooperativa debía ajustar "su estructura y funcionamiento a los principios cooperativos" establecidos en la propia Ley, sin referirse a los principios cooperativos de la $\mathrm{ACI}^{18}$. Dicción que fue sustituida por la reciente Ley 11/2019, de 20 de diciembre, de Cooperativas de Euskadi ${ }^{19}$ (LCPV), que dispone que dicha sociedad ajustará su estructura y funcionamiento "a los principios cooperativos de la Alianza Cooperativa Internacional, que serán aplicados en el marco de la presente ley", decantándose por un modelo impregnado de dichos principios, a los cuales alude de manera meramente enunciativa, tal y como ya hiciera el legislador de 1993, cuya E.M. argumentaba que se renunciaba a incluir un elenco de principios, por cuanto que más que ensayar enunciados de carácter puramente doctrinal, lo que debe procurar es fijar "garantías normativas" para la aplicación efectiva de los caracteres esenciales de la institución regulada.

En este sentido, las cooperativas son entidades con un marco jurídico influenciado por los valores y principios de la ACI, siendo, en nuestro Derecho, incorporados en todas las leyes de cooperativas, alcanzando fuerza normativa como principios jurídicos, lo que ha llevado a algún sector doctrinal a concebirlos como verdaderas

15. En esta sede, vid. GADEA SOLER, E., SACRISTÁN BERGIA, F. \& VARGAS VASSEROT, C.: Régimen jurídico de la sociedad cooperativa del siglo XXI: realidad actual y propuestas de reforma, Dykinson, Madrid, 2009, p. 38; y JULIÁ IGUAL, J.F. \& GALLEGO SEVILLA, L.P.: "Principios cooperativos y legislación de la sociedad cooperativa española: el camino hacia el fortalecimiento de su carácter empresarial”, REVESCO. Revista de Estudios Cooperativos, $\mathrm{n}^{\circ}$ 70, 2000, p. 2.

16. Vid. ALFONSO SÁNCHEZ, R.: "Los principios cooperativos como principios configuradores de la forma social cooperativa”, CIRIEC-España, Revista Jurídica de Economía Social y Cooperativa, no 27, 2015, p. 11; y MIRANDA, J.E. DE, op. cit., p. 69.

17. Ley 4/1993, de 24 de junio, de Cooperativas de Euskadi. Boletín Oficial del País Vasco (en lo sucesivo, BOPV) no 135 , de 19 de julio de 1993.

18. Vid. SANTOS DOMÍNGUEZ, M.A.: "La relación de los principios cooperativos con el Derecho", CIRIEC-España, Revista Juridica de Economía Social y Cooperativa, n 27, 2015, p. 113.

19. BOE no 14 , de 16 de enero de 2020. 
normas jurídicas, considerándose, incluso, parte del interés social o del orden público cooperativo ${ }^{20}$. Sin embargo, no es posible llevar esta opinión a sus últimas consecuencias, apreciándolas como reglas inmutables, sino como directrices de actuación, pues no se normativiza el principio formalmente considerado. No obstante, desde la Declaración sobre la Identidad Cooperativa de 1995 se ha avanzado con decisión, hasta el punto de que es posible formular un marco general que delimite la naturaleza de estos valores y principios, y de sus efectos sobre la normativa cooperativa vigente.

En esta línea, debe cuestionarse si existe un derecho subjetivo al ingreso, o, cuando menos, que el aspirante sea titular de un interés legítimo a ingresar en la cooperativa, que se ha venido reclamando por la ACI. Como regla general, puede afirmarse que no existe tal derecho. Sino que queda a discreción de la cooperativa el admitir o no a una persona que, cumpliendo con los requisitos exigidos, manifiesta su voluntad de asociarse, al primarse el carácter personalista de estas formaciones colecti$\operatorname{vas}^{21}$. Doctrina que ha quedado reflejada legislativamente en todas y cada una de las disposiciones autonómicas referentes a este aspecto. Valgan citar, a estos efectos, el art. 23.3 de la Ley 8/2006, de 16 de noviembre, de Sociedades Cooperativas de la Región de Murcia $^{22}$ (LSCRM); el art. 18.4 de la Ley 14/2011, de 23 de diciembre, de Sociedades Cooperativas Andaluzas ${ }^{23}$ (LSCA); el art. 18 de la Ley 6/2013, de 6 de noviembre, de Cooperativas de Cantabria ${ }^{24}$ (LCCANT); el art. 29.1 de la Ley 12/2015, de 9 de julio, de cooperativas de Cataluña ${ }^{25}$ (LCCAT); el art. 10.2 f) y g) del Decreto Legislativo 2/2015, de 15 de mayo, del Consell, por el que se aprueba el texto refundido de la Ley de Cooperativas de la Comunitat Valenciana ${ }^{26}$ (LCCV); o el art. 20 de la ya citada LCPV.

20. Vid. SANTOS DOMÍNGUEZ, M.A: El poder..., pp. 100 y 166.

21. La trascendencia jurídica de estos principios jurídicos se supedita a los términos en que hayan sido incorporados en las respectivas legislaciones internas. Vid. SERRANO Y SOLDEVILLA, A.D., op. cit., p. 293; y VARGAS VASSEROT, C.: "El principio cooperativo de puertas abiertas (adhesión voluntaria y abierta). Tópico o realidad en la legislación y en la práctica societaria”, CIRIEC-España, Revista Jurídica de Economía Social y Cooperativa, no 27, 2015, p. 161. Y, desde la vertiente opuesta, afirmando la existencia de un verdadero derecho subjetivo al ingreso o, cuanto menos, un interés legítimo, vid. PAZ CANALEJO, N.: "Principios...", pp. 27 y ss.

22. BOE no 111, de 9 de mayo de 2007.

23. BOE no 17 , de 20 de enero de 2012.

24. BOE no 284 , de 27 de noviembre de 2013.

25. BOE no 194 , de 14 de agosto de 2015.

26. Diario Oficial de la Comunidad Valenciana (en lo sucesivo, DOCV) no 7.529, de 20 de mayo de 2015. 
En consecuencia, la sociedad no viene obligada a aceptar cuantas solicitudes le sean presentadas, ya que ello provocaría un crecimiento "desmesurado" de su base social, debiendo tenerse en cuenta las características de la sociedad y las posibilidades de capacidad de sus instalaciones y servicios. Y ello en base a que el acuerdo del Consejo Rector constituye, exclusivamente, una declaración de voluntad, por la cual, los administradores, tras cerciorarse del cumplimiento de los requisitos estatutarios, aceptan la oferta realizada por los aspirantes a socio.

\section{Tratamiento del principio por la Alianza Cooperativa Internacional (ACI)}

\section{Consideraciones introductorias}

La cooperativa, desde el principio, se ha distinguido por la adecuación de sus acciones a unos principios de funcionamiento, conformadores, junto a los valores a los que aspira, de su identidad ${ }^{27}$. La ACI (en inglés, International Cooperative Alliance, $I C A$ ), al efecto, formula y revisa periódicamente los principios cooperativos, determinantes de las cualidades esenciales de las cooperativas, y que se erigen en pautas flexibles mediante las que se conforma su naturaleza democrática, otorgando un carácter informador a su funcionamiento, no pudiendo catalogarse de "principios" configuradores, sino de elementos configuradores del tipo cooperativo ${ }^{28}$. En esencia, son unos criterios mediante los cuales ponen en práctica sus valores de democracia, igualdad, equidad, solidaridad, etc., y que han de ser seguidos sistemáticamente. A este respecto, es posible afirmar que los principios cooperativos, dado su carácter de permanencia, determinan las cualidades esenciales que hacen que la cooperativa constituya un tipo social diferente. La propia ACI la conceptúa como una "asociación autónoma de personas que se han unido de forma voluntaria para satisfacer sus necesidades y aspiraciones económicas, sociales y culturales en común mediante una empresa de propiedad conjunta y gestión democrática" ${ }^{29}$.

27. Vid. MARTÍNEZ CHARTERINA, A., op. cit., p. 9.

28. Vid. ALFONSO SÁNCHEZ, R., op. cit., p. 58; y VARGAS VASSEROT, C.: "El nuevo (por diferente) marco legal de las sociedades cooperativas en Andalucía. El paso de una concepción social de la cooperativa a una economicista radical", Revista de Derecho de Sociedades (RdS), n 53, 2018.

29. Vid. ALIANZA COOPERATIVA INTERNACIONAL [ACI]: Declaración sobre la Identidad y principios cooperativos, XXXI Congreso de la Alianza Cooperativa Internacional, Manchester, 1995. Recuperado de http://www.ica.coop/coop/principles.html. 
Uno de estos principios fundamentales enumerados por la ACI es el de adhesión voluntaria y abierta, pues, los fundadores de la cooperativa de los Pioneros de Rochdale ya previeron la posibilidad de incorporación de nuevas personas a su base personal, al objeto de hacer partícipes a aquellas de los resultados de su actividad. En cuanto al reverso de la adhesión, esto es, la baja voluntaria, la persona socia había de notificar su intención secesionista con un mes de antelación ${ }^{30}$, como se observará con mayor detenimiento infra.

\section{La Declaración de la ACI sobre Identidad Cooperativa (Manchester, 1995). Posición de la Alianza sobre este principio}

La versión actual de los principios cooperativos se contiene en la "Declaración de la Alianza Cooperativa Internacional sobre Identidad Cooperativa”, adoptada en el XXXI Congreso celebrado en Manchester en 1995, conmemorativo de su centenario, disponiéndose que las cooperativas están basadas en los valores de autoayuda; autorresponsabilidad; democracia; igualdad; equidad; y solidaridad, al tiempo que percute en que los socios cooperativos hacen suyos los valores éticos de la honestidad, la transparencia, la responsabilidad y la vocación sociales. Y se enumeran siete principios, como son la adhesión voluntaria y abierta; la gestión democrática por parte de los socios/as; la participación económica por parte de los mismos; la autonomía e independencia; la educación, formación e información; la cooperación entre cooperativas; e interés por la comunidad. El movimiento cooperativo internacional admite la convivencia tanto de la cooperación "economicista o funcional", como de la cooperación "clasista o social", tendente, esta última, a la cooperación como movimiento social de reacción al sistema de gestión capitalista de las sociedades para la generación de riqueza. En cualquier caso, la formulación de los principios cooperativos que se realiza en 1995, como ya hiciera la de 1966, destaca por la unidad de los mismos, no siendo posible la inaplicación de uno de ellos sin poner en cuestión o en retroceso a los otros ${ }^{31}$.

Esta Declaración reformula los principios, particularmente, en lo atinente a la adhesión voluntaria y abierta, en el sentido de que las cooperativas son "organizaciones voluntarias, abiertas a todas las personas capaces de utilizar sus servicios y dispuestas a aceptar sus responsabilidades de ser socio, sin discriminación social, política, reli-

30. Principio, el de puertas abiertas, que se explicitaba en Rochdale como "libre adhesión y libre retiro".

31. Vid. PANIAGUA ZURERA, M.: "La sociedad-empresa cooperativa en la evolución de los modelos ius cooperativos en Espańa", Revista de Derecho de Sociedades (RdS), no 40, 2013, pp. 159-205. 
giosa, racial o de sexo". Formulación que se mantiene respecto del Congreso de la ACI en Viena, de 1966 (dispositiva de que, "la adhesión a una sociedad cooperativa debe ser voluntaria y estar al alcance, sin restricción artificial ni cualquier discriminación social, política, racial o religiosa, de todas las personas que puedan utilizar sus servicios y estén dispuestas a asumir las responsabilidades inherentes a la calidad de asociado"), aportando un incuestionable aliento ético, traducible en un compromiso de reconocer la dignidad esencial de los sujetos.

Como se observa, en la primera parte de esta rúbrica se incide en la voluntariedad en la adhesión y la apertura a todas las personas, percutiendo la $\mathrm{ACI}^{32}$ en que, "la gente elige voluntariamente participar y mantener un compromiso con su cooperativa. No se puede forzar a la gente a que coopere. Unirse e implicarse con los demás para satisfacer determinadas necesidades y aspiraciones comunes, tanto económicas como sociales y culturales, es un acto voluntario". En consecuencia, este principio es el más poderoso, en tanto que manifestación del altruismo cooperativo, al pretender que todos sus miembros se beneficien de las ventajas de la cooperación. De hecho, el movimiento cooperativo mundial lo incorporó como primer principio cooperativo en la primera definición de los principios cooperativos realizada por la ACI en 1937, en París. Pero, al mismo tiempo, es el más infravalorado, ya que, si no caben discriminaciones, $y$, siendo la cooperativa una entidad accesible a todas las personas que quieran participar de su estructura y se muestren dispuestas a cumplir su normativa, sin embargo, en multitud de cooperativas sus gestores impiden el acceso a personas que se reputan aptas para formar parte de las mismas. Insiste la ACI en que la afiliación abierta a todas las personas "implica que no debe existir un umbral muy alto para convertirse en miembro".

Por otra parte, la realidad social demuestra que han sido escasos los supuestos de discriminaciones anticooperativas, ya se fundamenten en razones sociales, políticas, religiosas, raciales o de sexo, como obstáculo para el ingreso de nuevos socios/as. Han sido más frecuentes los casos de inadmisión con base en la no superación del umbral económico deseable en la cooperativa, por no poder asumir un compromiso anual mínimo, ya sea de compras, de ventas, o de demanda de servicios.

Desde la perspectiva contraria, recalca la Alianza que la afiliación voluntaria y abierta también consiste en que "los miembros son libres de dejar de serlo si así lo deciden”, debiendo ser limitadas las restricciones de salida. 


\section{Recepción del principio por el ordenamiento cooperativo español y su necesaria armonización}

\section{La especial configuración del Derecho cooperativo en España: la dispersión normativa como rasgo característico}

La cooperativa, como se viene ensalzando, ha de ajustarse a los valores y principios formulados por la ACI, en tanto que la dotan de una función social y de interés general. Y ello en base a que dichos principios tienen una validez anterior y extraña al Derecho, debiendo ser desarrollados por las leyes de cooperativas. En este sentido, la legislación cooperativa, desde la promulgación de la CE de 1978, ha alcanzado un elevado desarrollo en un marco jurídico definido por tres pilares fundamentales: su art. 129.2; los Estatutos de autonomía de las CC.AA.; y la doctrina del Tribunal Constitucional (TC).

De este modo, en primer lugar, el art. 129.2 CE, con el mandato de fomento de las cooperativas, ha de interpretarse en el sentido de concebir al cooperativismo como fórmula de integración y participación "de todos" en la vida económica, cultural y social, a la luz del art. 9.2 CE, haciendo de la cooperativa el único modelo de empresario que los poderes públicos están obligados a fomentar. En segundo lugar, y en relación con los mencionados Estatutos autonómicos, dado que la norma fundamental no reserva competencia alguna al Estado en materia de cooperativas, las CC.AA. ostentarán las competencias que hayan asumido en la norma estatutaria correspondiente. Por último, en esta sede, y como en la actualidad resulta pacífico, el $\mathrm{TC}^{33}$ ha dispuesto que la competencia exclusiva para regular por ley las cooperativas corresponde a las CC.AA., al no estar comprendida dentro de la legislación mercantil (art. 149.1. $\left.6^{\circ} \mathrm{CE}\right)$.

A pesar de que el dictado de la LCOOP supuso un acicate en la regulación del tipo social, su tradicional consideración como entidades no mercantiles motivó el traspaso de competencias en materia legislativa a las CC.AA. De hecho, en la actualidad, todas (a excepción de Ceuta, Melilla y Canarias ${ }^{34}$ ) han asumido competencias exclusivas para regular a las cooperativas que queden sometidas a su ámbito de aplicación, esto es, aquellas que, teniendo su domicilio social en esa C.A., desarrollen la actividad cooperativizada con sus socios dentro de la misma, así como aquellas

33. Se alude a la ya mencionada STC 72/1983, con ocasión del recurso de inconstitucionalidad interpuesto contra determinados artículos de la Ley 1/1982, sobre Cooperativas del País Vasco.

34. Comunidad Autónoma que, a fecha de redacción de este escrito, y por medio del Proyecto de Ley de Sociedades Cooperativas de Canarias, publicado en el Boletín Oficial del Parlamento de Canarias (BOPC) el 11 de marzo de 2019, pretende colmar las aspiraciones del cooperativismo de dicho territorio. 
cuya actividad principal y el mayor número de personas socias radiquen en dicha C.A. ${ }^{35}$. De esta forma, además de la LCOOP estatal, en la actualidad son dieciséis las CC.AA. que disponen de ley cooperativa propia.

Por consiguiente, no ha existido razón objetiva para una diversa regulación de la cooperativa en cada C.A., sino que, de esta manera, se aumenta sobremanera la complejidad del sistema jurídico. Hay que ser proclives a reivindicar una unidad de régimen jurídico, indiscutida en el resto de formas sociales, y una mínima armonización legislativa como la existente en el Derecho comunitario europeo en torno a dichas entidades. A este respecto, la conexión entre la cooperativa y el Derecho de la UE se ha analizado desde un punto vista muy abstracto, sin plasmarse en realidades normativas concretas. Por cuanto que la falta de homogeneidad en la regulación de la cooperativa española devendría en un resultado "perverso", profundizándose en el particularismo normativo. Lejos de fomentar el impulso a su creación, dicha disimilitud se erige en barrera de entrada para el desarrollo del cooperativismo, dando lugar a que, contrariamente, se opte por formas de organización empresarial provistas de un régimen jurídico más estable, huyendo del tipo social cooperativo.

\section{Situación normativa estatal vigente: La Ley 27/1999, de 16 de julio, de Cooperativas}

La promulgación de la vigente LCOOP, que sustituyó a la anterior Ley General de Cooperativas estatal de $1987^{36}$ (en lo sucesivo, LGC de 1987), la cual, derogaba a la vetusta Ley 52/1974, de 19 de diciembre, General de Cooperativas ${ }^{37}$, despertó el interés por este tipo social, sirviendo a su consolidación empresarial, al tiempo que suponía la adaptación de la legislación cooperativa a las nuevas necesidades. En este sentido, la LCOOP (de aplicación, por su carácter supletorio, a las cooperativas que desarrollen su actividad en el territorio de más de una C.A., o en las ciudades de Ceuta y Melilla, como dispone su art. 2), contiene en su art. 1.1 la mención a los principios de la ACI de una forma escueta y a propósito del concepto de cooperativa, de donde se desprende una minusvaloración de la relevancia legal que ostentan dichos principios, lo que no obsta para que sean entendidas como normas directamente aplicables. Ya en su E.M. disponía que, “(...) el objetivo de la nueva Ley es precisa-

35. Vid. GARCÍA-GUTIÉRREZ FERNÁNDEZ, C.: "La necesidad de la consideración de la sociedad cooperativa como entidad mercantil para la adecuada legislación”, REVESCO. Revista de Estudios Cooperativos, no 66, 1998, p. 211.

36. Ley 3/1987, de 2 de abril, General de Cooperativas (BOE no 84, de 8 de abril de 1987).

37. BOE no 305, de 21 de diciembre de 1974. 
mente que los valores que encarna la figura histórica del cooperativismo -respuesta de la sociedad civil a los constantes e innovadores condicionamientos económicossean compatibles y guarden un adecuado equilibrio con el fin último del conjunto de socios, que es la rentabilidad económica y el éxito de su proyecto empresarial".

Así pues, la normativa cooperativa estatal no mostraba problema de asimilación de los principios cooperativos incluso con anterioridad a la reformulación de Manchester de 1995. Producida esta, el status quo no ha variado, manteniendo su virtualidad los elementos clave que configuran la identidad cooperativa (a saber, voluntariedad; autonomía; gestión democrática, etc.). En este sentido, el art. 1 LCOOP establece que la cooperativa "es una sociedad constituida por personas que se asocian, en régimen de libre adhesión y baja voluntaria, para la realización de actividades empresariales, encaminadas a satisfacer sus necesidades y aspiraciones económicas y sociales, con estructura y funcionamiento democrático, conforme a los principios formulados por la alianza cooperativa internacional (...)".

Como se observa, el principio de libre adhesión y baja voluntaria, pese a que podría entenderse incluido entre los principios "formulados por la ACI" (art. 1.1 LCOOP, in fine) aparece en la vigente Ley estatal separado de aquellos, lo que evidencia su relevancia, en cuanto que parte intrínseca de la definición de cooperativa. De hecho, la extinta LGC de 1987 ya regulaba la posibilidad de que las cooperativas pudieran realizar operaciones con terceros no socios, al disponer su E.M. que, "la exigencia de potenciar cuanto favorezca al desarrollo de la actividad empresarial de las cooperativas hace preciso, entre otras cosas, aceptando con pragmatismo las realidades del mercado, abrir las posibilidades para determinadas clases de cooperativas de realizar operaciones con terceros no socios", siendo consecuente la doctrina de la época $^{38}$ en que la participación de los terceros en las operaciones que constituyen el objeto de la cooperativa no ha de "determinar automáticamente la descalificación de esta”.

El art. 12.1 LCOOP concretiza las personas aptas para adquirir la condición de persona cooperativista, estableciendo que lo son "tanto las personas físicas como jurídicas, públicas o privadas y las comunidades de bienes”, agregando el apartado segundo que los estatutos podrán establecer los requisitos necesarios para adquirir tal condición. No obstante, esta libertad de configuración estatutaria no es absoluta, sino que se encuentra limitada por el meritado principio configurador de puertas abiertas, no pudiéndose fijar requisitos que hagan de la cooperativa una sociedad cerrada, cuya interpretación habrá de hacerse restrictivamente.

38. A saber, vid. ARCO ÁLVAREZ, J.L. DEL: "Los Principios cooperativos en la Ley General de Cooperativas", Estudios cooperativos, no 36-38, 1975-1976, p. 30. 
Por su parte, el art. 13 LCOOP regula el proceso de admisión de nuevos socios/ as, que se iniciará mediante solicitud escrita formulada por el aspirante al Consejo Rector, a resolver en un plazo no superior a tres meses. Conviene recordar que la derogada LGC de 1987 imponía que figurasen en los estatutos las condiciones necesarias para devenir persona socia, estipulación que se terminaría estimando de inapropiada. Al mismo tiempo, esta LGC entendía que el transcurso del plazo para resolver la solicitud (sesenta días desde el recibo de la solicitud) por parte del Consejo Rector había de entenderse como silencio negativo, y, por tanto, la solicitud, rechazada, abriendo la vía del recurso. Por el contrario, la vigente LCOOP estipula que, transcurrido el plazo sin haberse adoptado decisión, se entenderá estimada, optando por la solución más favorable para el aspirante. Debe reafirmarse lo dispuesto supra en relación a que el solicitante carece de un derecho a adquirir la condición de socio/a, pues la decisión sobre su admisión debe guiarse por razones de conveniencia, que solamente a la cooperativa corresponde valorar, conforme a su modelo ius cooperativo economicista ${ }^{39}$.

Por otro lado, el art. 17 LCOOP se refiere a la baja voluntaria, derecho reconocido en el art. 16.2.f) de su texto, en tanto que acto unilateral del socio en el que no interviene la voluntad de los órganos societarios, y que podrá ser ejercitado en cualquier momento (ad nutum), sin necesidad de autorización, como muestra de respeto a la individualidad de la person ${ }^{40}$, que no ha sido, tampoco, objeto de modificaciones relevantes, sufriendo únicamente alteración el plazo de preaviso escrito al Consejo Rector, que pasó de tres meses a un año. Y este límite de un año igualmente se observa en algunas leyes autonómicas, como, v.gr., en el art. 20.1 de la Ley 5/1998, de Cooperativas de Galicia ${ }^{41}$, de 18 de diciembre (en lo sucesivo, LCG). No obstante, se imponen unos plazos menores en distintas disposiciones, concretamente, de seis (LSCA, art. 23.1) y de tres meses (LCPV, art. 26.1).

Este art. 17 LCOOP, a diferencia del precepto homónimo de la LGC de 1987 (art. 32.2) no menciona justa causa para causar baja. Esta última aludía (art. 33.3) a que el "socio que hubiese salvado expresamente su voto o estuviese ausente, disconforme con cualquier acuerdo de la Asamblea General, que implique la asunción

39. Se explaya sobre las características de ambos modelos, economicista o social, PANIAGUA ZURERA, M., op. cit., pp. 159-205.

40. Vid. TRUJILLO DÍEZ, I.J., op. cit., p. 1.349. Entre la jurisprudencia más reciente, la SAP de Zaragoza, de 18 de diciembre de 2019 (JUR 2020, 44639), por la cual, la separación de la persona cooperativista se configura "como derecho ad nutum, que no precisa alegación justificativa alguna, y se produce en el momento mismo en el que manifiesta su voluntad al efecto". Recalcando que, "(...) es el Consejo Rector quien debe calificar la baja como justificada o no justificada (art. 22 LCAR) pero lo que no puede hacer es denegarla”. 
de obligaciones o cargas gravemente onerosas, no previstas en los Estatutos, podrá darse de baja, que tendrá la consideración de justificada, mediante escrito dirigido al Consejo Rector dentro de los cuarenta días a contar del siguiente a de la adopción del acuerdo". A su vez, la vetusta LGC de 1974 (art. 9.2) también facultaba para limitar la admisión de socios/as por dicha justa causa, al tiempo que establecía un límite insuperable, pues entre los motivos que fundamentaran la misma no podía encontrarse la discriminación por motivos políticos, religiosos, de raza, sexo o estado civil. Desde el parecer de la doctrina esto se entendió para "dar satisfacción a ciertos criterios ideológicos imperantes en el extranjero", siendo calificada como una norma que abría la puerta a la "politización de las cooperativas" de discriminación por los mencionados motivos desaparece con la promulgación de la vigente LCOOP.

Asimismo, las consecuencias del incumplimiento del preaviso fueron relajadas por el legislador de 1999, al preverse, exclusivamente, la indemnización de daños y perjuicios, no siendo dicha vulneración impeditiva de la baja, por cuanto que ello conculcaría la naturaleza "aperturista" de la cooperativa ${ }^{43}$. La jurisprudencia posterior convino, en relación con un hipotético compromiso de permanencia estatutario, que el mismo limita un derecho del socio/a a causar baja voluntaria, debiendo esta norma de fijación de dicho período de permanencia ser objeto de interpretación restrictiva, atendiendo al brocardo de favorabilia sunt amplianda et odiosa restringenda ${ }^{44}$.

En lo relativo a las causas determinantes de la baja, se ha optado por un criterio favorable a la libre salida de la persona socia, al establecer el art. 17.2 que, si en el plazo de tres meses, o el menor que fijen los estatutos, el Consejo Rector no ha resuelto sobre la calificación y efectos de la baja del socio/a cesante, el mismo podrá entender la baja justificada.

En suma, el legislador estatal ha querido que sea libre la entrada y salida de socios/ as, siguiendo el principio cooperativo expuesto de la "adhesión voluntaria y abierta".

42. Vid. LLUIS Y NAVAS, J.: "La evolución de las directrices fundamentales de la legislación cooperativa española (1931-1975)”, Estudios cooperativos, no 39, 1976, p. 26.

43. En esta dirección, el TS ya se pronunció en la Sentencia de 16 de marzo de 1998 (RJ 1998, 1568), a cuya dicción se emplaza.

44. Valga citar, a este respecto, la STS de 25 de enero de 2008 (RJ 2008, 222). 


\section{Las leyes autonómicas de sociedades cooperativas}

Como se ha expuesto, la cooperativa es una sociedad mercantil a todos los efectos, como lo refleja el art. 1 LCOOP, cuando alude a que su objeto es la realización de actividades empresariales. Si bien, el propio TS discrepa (vid., STS de 1 de febrero de 1992, RJ 1992, 867), arguyendo que, "la Constitución otorgó a las Comunidades Autónomas la competencia sobre Cooperativas, lo que nunca hubiera podido hacer si se tratase de entidades mercantiles, al tener el Estado la competencia exclusiva sobre la legislación mercantil, según el artículo 149.1. $6^{\circ}$ de la Constitución”. El art. 129.2 CE ordena a los poderes públicos fomentar, mediante una legislación adecuada, las sociedades cooperativas, a través de la asunción de las competencias exclusivas por las CC.AA. Dicho mandato se está llevando a cabo mediante la regulación descentralizada de todo el ámbito sustantivo en cada una de las CC.AA. (la última, la LCPV, que en su art. 157 preceptúa el fomento de los principios cooperativos) y por parte del Estado, dando lugar a un desafortunado desbordamiento legislativo carente de coherencia, que impide el desarrollo pleno de las cooperativas. Entidades que, no se olvide, han de competir en el mercado con instituciones capitalistas que disponen de una regulación uniforme ${ }^{45}$.

Las primeras CC.AA. que hicieron uso de su facultad legislativa cooperativa fueron el País Vasco, con su Ley de Cooperativas de $1982^{46}$; y Cataluña, con su Ley de Cooperativas de $1983^{47}$, ambas derogadas, dando satisfacción a las aspiraciones del cooperativismo vasco y catalán de disponer de una normativa propia. Pero no fue hasta la promulgación de la Ley de Cooperativas de la Comunidad Valenciana de $1985^{48}$, art. 3, cuando una ley autonómica reconoció que dicho tipo social había de inspirarse en los principios cooperativos formulados por la ACI, entre ellos, el de libre adhesión. A partir de entonces, los diferentes ordenamientos cooperativos articularían un régimen destinado a dicha adhesión, con un esquema similar al previsto por la LGC de 1974. Posteriormente, ante la necesidad de reformulación de tales principios para responder a las demandas del mercado, se llega a la ya mencionada Ley vasca de 1993 (derogada, a la postre, por la aludida LCPV de 2019), primera ley cooperativa española que es posible catalogar de economicista, derogatoria de su

45. Vid. GARCÍA JIMÉNEZ, M.: "La necesaria armonización internacional del Derecho cooperativo", REVESCO. Revista de Estudios Cooperativos, n 102, 2010, pp. 2 y ss.

46. Ley 1/1982, de 11 de febrero, sobre Cooperativas (BOE no 100, de 26 de abril de 2012).

47. Ley 4/1983, de 9 de marzo, de Cooperativas de Cataluña (DOGC no 313, de 18 de marzo de 1983).

48. Ley 11/1985, de 25 de octubre, de Cooperativas de la Comunidad Valenciana (DOGV no 300, de 31 de octubre de 1985). 
homónima de 1983, y que supuso un auténtico referente para el resto de legislaciones cooperativas a la hora de configurar un modelo societario observando los valores y principios proclamados por la ACI, al tiempo que dotaba a la cooperativa de un cobertura legal para competir en un mercado en constante fluctuación. De hecho, su E.M. establecía que, con la misma, se pretendían eliminar las "trabas preexistentes para el adecuado desarrollo de nuestras cooperativas, con el objetivo final de que estas puedan situarse en el mercado con idénticas posibilidades que el resto de las empresas con las que deben competir".

Asimismo, aparecen leyes nuevas de CC.AA. que no habían hecho uso de su facultad cooperativa, como Extremadura ${ }^{49}$, Galicia (a través de la mencionada LCG), Aragón ${ }^{50}$, o Madrid ${ }^{51}$, que continuaron el proceso de incorporación de los principios emanados de Rochdale y que fueron reinterpretados por la ACI. En consecuencia, los principios cooperativos se elevaron a la categoría de auténtica fuente del Derecho $^{52}$, actuando como fuentes supletorias, en defecto de Ley o de costumbre.

Se produjo, así, una positivización de los principios, siendo, su eficacia, la misma que la de la ley que a ellos remite, en tanto que la cooperativa debe ajustar su estructura, funcionamiento y organización. Así lo escenificó la LCCAT -como ya hiciera previamente la Ley de $2002^{53}$-, al establecer que dichos principios "han de aplicarse al funcionamiento y a la organización de las cooperativas, han de incorporarse a las fuentes del derecho cooperativo catalán como principios generales (...)”, al aportar un criterio interpretativo de dicha LCCAT.

Otras leyes autonómicas, como la LCCANT, aunque renuncian a incluir un elenco, en la intención del legislador cántabro se hallaba la idea de evitar que una Ley, con vocación de permanencia, quedase desfasada en caso de redefinición de los principios por la ACI. Para, finalmente, dejar establecido que la sociedad cooperativa "se ajustará a los principios cooperativos formulados" por la ACI, en los términos resultantes de dicha Ley (art. 2), llevando a cabo una enumeración de los mismos en su Preámbulo.

49. Ley 2/1998, de 26 de marzo, de Sociedades Cooperativas de Extremadura (BOE no 128, 29 de mayo de 1998).

50. Ley 9/1998, de 22 de diciembre, de Cooperativas de Aragón (BOE no 23, de 27 de enero de 1999).

51. Ley 4/1999, de 30 de marzo, de Cooperativas de la Comunidad de Madrid (BOE no 131, de 2 de junio de 1999). En lo sucesivo, LCCM.

52. Citando, literalmente, lo dispuesto por el art. 3 de la derogada Ley 8/2003, de 24 de marzo, de Cooperativas de la Comunidad Valenciana (BOE no 87, de 11 de abril de 2003), clarificadora a este respecto.

53. Ley 18/2002, de 5 de julio, de cooperativas catalanas, en lo sucesivo, LCCAT de 2002 (BOE n 179, de 27 de julio de 2002). 
En lo que atañe al principio de puertas abiertas, todas estas normas autonómicas lo reconocen explícitamente, algunas, remitiendo a los principios de la ACI, como los art. 2 de la Ley Foral 14/2006, de 11 de diciembre, de Cooperativas de Navarra ${ }^{54}$ $(\mathrm{LFCN})^{55}$; art. 1.1 LCCM; art. 1.4 LCG; art. 2 LSCEX; art. 2.2 de la Ley 11/2010, de 4 de noviembre, de Cooperativas de Castilla-La Mancha ${ }^{56}$ (LCCLM); art. 2.1 LCRM; art. 2.1 del Decreto Legislativo 2/2014, de 29 de agosto, del Gobierno de Aragón, por el que se aprueba el texto refundido de la Ley de Cooperativas de Aragón $^{57}$ (LCAR), que, expresamente, dispone que las cooperativas "deberán ajustar su estructura y funcionamiento a los principios cooperativos y, en especial, los fijados por la Alianza Cooperativa Internacional, que serán aplicados en el marco de la presente Ley"; o la más reciente LCPV ${ }^{58}$, art. 1.2, alusiva de que la entidad cooperativa "deberá ajustar su estructura y funcionamiento a los principios cooperativos de la Alianza Cooperativa Internacional, que serán aplicados en el marco de la presente ley". Otras, directamente en su articulado, como el art. 4 LSCA, que, al contrario que su precedente, el art. 2.2 LSCA de 1999, omite la referencia a la variabilidad del capital social, signo distintivo, como ya se ha expuesto, del carácter abierto de la cooperativa. En cualquier caso, para conocer la concreta concepción del principio en cada una de las mismas habrá que observar si se ha respetado el contenido particular que la Declaración sobre la Identidad Cooperativa de 1995 otorgó a dicho principio. Similar tenor es el ofrecido por el art. $3 \mathrm{LCCV}$, al disponer que las cooperativas valencianas "se inspirarán en los valores cooperativos (...)".

No existe, como se advirtió, un derecho subjetivo al ingreso, habiéndose otorgado, desde los diferentes parlamentos autonómicos, diversa respuesta. Por ejemplo, la LCG, en su art. 19, no reconoce este derecho, exigiendo, exclusivamente, que el Consejo Rector resuelva sobre la solicitud "motivadamente". Por el contrario, se desprende este pretendido derecho en la LCCLM, que en su art. 26.1, bajo la rúbrica "Derecho a la admisión", establece que "toda persona que reúna los requisitos del artículo anterior y esté interesada en utilizar los servicios de la cooperativa, tiene derecho a ingresar como socia, salvo que lo impida una causa justa derivada de la actividad u objeto social de la cooperativa”. Al tiempo que dispone que la inadmisión será

54. BOE no 149, de 4 de enero de 2007.

55. Como otrora hiciera, en su art. 2, su antecesora, la Ley 12/1996, de 2 de julio, de Cooperativas de Navarra (BOE no 245, de 10 de octubre de 1996).

56. BOE no 37, de 12 de febrero de 2011.

57. BOE no 176, de 9 de septiembre de 2014.

58. Sobre la que se incidirá infra, en el apdo. V.1, denominado "Análisis de las novedades relativas a este principio. 
"motivada" y sólo podrá tener lugar "por causa justificada, derivada de los estatutos o de alguna disposición legal, o por imposibilidad técnica o estructural debidamente acreditada”. Idéntico paradigma es reproducido por la LSCA, art. 18.4, tal y como dispusiera la Ley de 199959, art. 36.2, al estipular que el acuerdo denegatorio fuera siempre motivado y determinado "por causa justificada, derivada de los Estatutos, de alguna disposición legal imperativa, o de imposibilidad técnica”. En cualquier caso, la denegación de la solicitud de ingreso ha de estar fundamentada en el respeto al principio de libre adhesión, no debiendo utilizarse excusas basadas en restricciones artificiales a ingresos de nuevos socios/as. En la misma línea de la ley manchega, la Ley 4/2010, de 29 de junio, de Cooperativas, de Asturias ${ }^{60}$ (LCAS), art. 22.1 prescribe que toda persona interesada en formar parte de la cooperativa tiene "derecho solicitar el ingreso como socio y, en su caso, a ser admitido".

Desde esta perspectiva, el principio de puertas abiertas no puede ser concebido como un derecho absoluto a ser admitido ${ }^{61}$. Sus fronteras vendrán definidas por la autonomía estatutaria, determinante de los requisitos para entrar a formar parte de la cooperativa. En este sentido, la doctrina ${ }^{62}$ advierte que la configuración estatutaria "caprichosa" o "arbitraria" contradeciría los fundamentos del principio. Y, precisamente, algunas disposiciones autonómicas como el art. 18.1 LSCA; o el ya mencionado art. 29.1 LCCAT, entregan a la competencia exclusiva de los estatutos la concreción de esos requisitos (aludiendo, literalmente, a "condiciones objetivas"; o a "requisitos objetivos para la admisión"), sobrepasando, con creces, dichos límites. De hecho, la LGC de 1987, en su art. 31.1, incluía la prohibición de vincular los requisitos necesarios para ser socio a "motivos políticos, sindicales, religiosos, de nacionalidad, sexo, raza o estado civil", salvo que fueran incompatibles con el objeto social, en clara concordancia con el principio de neutralidad política y religiosa. Axioma, que, en ningún caso, la Declaración de Manchester de 1995 fijaba como vinculado al principio de adhesión voluntaria y abierta, en el sentido de que se pudiera infringir por razones políticas, religiosas, raciales o de sexo. Previsión que se ha mantenido en

59. Ley 2/1999, de 31 de marzo, de Sociedades Cooperativas Andaluzas (BOE no 107, de 5 de mayo de 1999).

60. $\mathrm{BOE} \mathrm{n}^{\circ} 232$, de 24 de septiembre de 2010.

61. En palabras de BORJABAD BELLIDO, J.V.: "Los principios cooperativos con especial atención al principio de libre admisión y baja voluntaria, su formulación por la A.C.I. y su acogimiento por la legislación española", Anuario de la Fundación Ciudad de Lleida, n² 24, 2013, p. 170; se trataría, más bien, de un principio de puerta "entreabierta" o "entornada", poniendo énfasis en que la competencia para decidir la admisión reside en los órganos sociales.

62. Vid. MORILLAS JARILLO, M.J. \& FELIÚ REY, M.I., op. cit. 
leyes autonómicas como la LFCN, en su art. 22.2, al disponer que, "no podrán ser causas denegatorias de la admisión las vinculadas a ideas políticas, sindicales, religiosas, de raza, lengua, sexo o estado civil". Se muestra más acorde con los postulados que aquí se defienden la LCG, cuando en su art. 19.1 dispone que, "para ingresar en calidad de socio en una cooperativa, el solicitante deberá cumplir los requisitos legales y estatutarios para adquirir dicha condición", agregando que dichos requisitos no pueden "quedar vinculados a motivos ilícitos o inconstitucionales".

No obstante, el principio de puertas abiertas no se entiende quebrado, debido al establecimiento de un sistema de garantías en aras de salvaguardar el interés del aspirante, pudiendo impugnar el acuerdo denegatorio del Consejo Rector en el plazo de veinte días desde la notificación del acuerdo de dicho órgano, ante el Comité de Recursos o, en su defecto, ante la Asamblea General (art. 13 LCOOP). Posibilidad impugnatoria que se justifica por el grado de discrecionalidad de que gozan los administradores/as cooperativistas para dar entrada a nuevos socios/as, cuando estimen que no reúnen las condiciones precisas o, aun poseyéndolas, su incorporación afecta negativamente al interés general de la cooperativa. En consecuencia, es necesario que exista, al margen de la necesaria motivación del acuerdo denegatorio, un medio tuitivo que permita contrastar la legitimidad de la decisión tomada por el órgano rector, atendiendo a la función social que otorga virtualidad al principio de adhesión voluntaria y libre, evitándose que dicho órgano deniegue de forma arbitraria la entrada en la sociedad ${ }^{63}$. En la legislación autonómica, en este sentido se expresa la LCCAT, art. 29.5, cuando estipula que la denegación de la admisión como socio es susceptible de recurso por la persona solicitante "ante la asamblea general o, en su caso, ante el comité de recursos, en el plazo de un mes a contar desde la fecha de la notificación del acuerdo del consejo rector o transcurrido el plazo previsto para dictar resolución (...)". Recurso que, como ejemplifica la ley catalana, habrá de ser resuelto en el plazo máximo de tres meses, debiendo entenderse el silencio como desestimatorio. Otros textos normativos, como la LCCM, art. 19.5, sin embargo, optan por reducir el plazo de que dispone el Comité de Recursos para solventar el mismo a treinta días.

Por otra parte, y en lo que atañe a los recursos por vía judicial, han sido muchas las legislaciones autonómicas que han optado por contemplar la posibilidad de que el aspirante impugne el acuerdo que resuelve el recurso contra la denegación ante el Juez de lo Mercantil (véase la LSCA, en su Reglamento; la LCCAT, art. 29.6, al disponer que el acuerdo que resuelva los recursos interpuestos ante la asamblea general o el Comité de Recursos será "susceptible de recurso ante la jurisdicción ordinaria"; o

63. Vid. SERRANO Y SOLDEVILLA, A.D., op. cit., pp. 180, 249 y ss.; y VARGAS VASSEROT, C.: "El principio...”, p. 34. 
la LCG, que, en su art. 20.5, dispone que "los acuerdos del órgano de administración sobre la calificación y los efectos de la baja de la persona socia podrán ser impugnados ante la jurisdicción competente (...)"; o, por último, la LCAR, art. 17.4 in fine, dispositivo de que, "(...) la resolución será recurrible ante la jurisdicción ordinaria”). No obstante, textos como la LCOOP no se pronuncian en este sentido.

En cualquier caso, el solicitante debe poder recurrir en vía arbitral o judicial, no bastando con que disponga de recursos propios del Derecho de sociedades, como la impugnación de los acuerdos sociales ${ }^{64}$; la exigencia de responsabilidad al órgano de administración; y los mencionados recursos ante la Asamblea General o el Comité de Recursos (que agotan la vía cooperativa de recursos), pues, de modo contrario, padecería una evidente indefensión. Si bien, como es claro, habrá de agotarse previamente la vía cooperativa. Por otra parte, la protección jurisdiccional del principio de puertas abiertas se erige en elemento clave a la hora de estudiar la transmisión de las aportaciones, no pudiendo negarse la entrada en la cooperativa al aspirante cumplidor de los requisitos estatutarios.

Desde distinta perspectiva, en relación con las operaciones con terceros, y como caracterización de la cooperativa como entidad que no puede subsistir exclusivamente con cargo a las aportaciones de sus socios/as, puede observarse el art. 7 LSCA ${ }^{65}$, que instaura el principio general de liberalización de este tipo de operaciones, al disponer que, "podrán realizar con terceras personas las actividades y servicios que constituyan su objeto social, sin más limitaciones que las establecidas en la presente ley, en otras disposiciones de carácter sectorial que les sean de aplicación o en sus propios estatutos", permitiendo una amplia operatividad de la cooperativa con no socios/as.

Efectivamente, la anterior LSCA de 1999 (art. 7), disponía que, "las sociedades cooperativas andaluzas podrán realizar, con terceros no socios, las actividades y servicios que constituyan su objeto social, únicamente en los casos previstos en la presente Ley y con las limitaciones y condiciones en ella establecidas", partiendo del carácter excepcional de las operaciones con no socios. Por su parte, el apdo. 2 de la derogada Ley andaluza agrega que la Administración podía "autorizar (...) la realización o, en su caso, ampliación de actividades y servicios con terceros a toda sociedad cooperativa, por el plazo y hasta la cuantía que fije la autorización (...)", haciendo depender

64. A este respecto, en determinadas CC.AA. es posible que los Estatutos sociales incorporen cláusulas de sometimiento a arbitraje.

65. Ley que, a este respecto, reformula los principios cooperativos, en aras de su adaptación evolutiva, lo que denota un cierto alejamiento de la formulación de la ACI. 
dicha anuencia de que se dieran las "circunstancias concurrentes", en clara reminiscencia a lo dispuesto en el art. 7 de la derogada Ley de $1985^{66}$.

Similar dirección es la seguida por la LSCRM, art. 6, que dispone que las entidades cooperativas "podrán realizar actividades y servicios cooperativizados con terceros no socios sin más limitación que las establecidas por sus propios Estatutos sociales"; o por la LCCLM, art. 8, al preceptuar que las cooperativas podrán realizar "libremente actividades y servicios cooperativizados con terceros no socios sin más límites que los previstos por esta Ley (...)", conservando la anquilosada condicionalidad de tales operaciones a que los estatutos no las prohíban o constriñan cuando lo "consideren oportuno". Dicción que encuentra justificación en el hecho de que lo que caracteriza a las cooperativas no es que puedan o no llevar a cabo actividades cooperativizadas con terceros, sino que, de forma necesaria, han de realizarlas con los socios, sin menoscabar el carácter abierto del tipo social.

\section{Modificaciones legislativas recientes en las CC.AA. El objetivo de la necesaria armonización normativa en torno a este principio}

\section{Análisis de las novedades relativas a este principio}

a) Concepto de cooperativa y principios formulados por la ACI

En este apartado V se efectuará un análisis de las más recientes modificaciones de las leyes cooperativas autonómicas en relación con el principio de libre adhesión y baja voluntaria. Se halla refrendo en torno a la relevancia adquirida por los principios cooperativos instaurados por la ACI, en tanto que están presentes de una manera u otra, ya sea a través de su incorporación expresa, ya sea haciéndolos ver como principios de elaboración propia, como es el caso de la LSCA, que, efectivamente, "reformula" dichos principios. En este sentido, las leyes autonómicas parten de los mismos, en cuanto que determinan la particular idiosincrasia del tipo social, distinguiéndolo de otras formas empresariales.

A pesar de que la mayoría de CC.AA. integran de modo expreso los principios de la ACI en su articulado, no han faltado algunas que, ya desde su E.M. traslucen un inusitado desapego por los mismos, como es el caso de la Ley 9/2018, de 30 de octubre, de sociedades cooperativas de Extremadura ${ }^{67}$ (LSCEX), que, siguiendo la 
línea marcada por su predecesora de 1998, de su dicción y de cierta doctrina ${ }^{68}$ se infiere que el "sacralizar" los meritados principios supone un lastre para el desarrollo de la cooperativa, al desvirtuarse sus rasgos propios y su singularidad respecto de los entes capitalistas, afirmándose en su E.M., que, "(...) para respetar el perfil tipológico de corte participativo que la Constitución dota a la sociedad cooperativa, la Ley, recogiendo el sentir y preocupación del movimiento cooperativo, se ha preocupado menos de los principios y de las alianzas, y más de desarrollar una legislación cooperativa comparable, desde el punto de vista de su nivel técnico, con las Leyes de sociedades de capital". De hecho, aun cuando en el art. 1 LSCEX se alude a que, en la cooperativa, las personas socias "se unen de forma voluntaria", no se contiene referencia alguna a este principio como propio de la ACI, optando por una definición laxa, tratando de no mentar dicho "principio" y de reforzar la independencia del legislador respecto de las formulaciones privadas internacionales al regular el tipo social cooperativo ${ }^{69}$.

A este respecto, en la LSCEX se concibe a la cooperativa como entidad de base mutualista, desde una visión alejada del interés capitalista, no deduciéndose, en norma alguna, que la misma haya pasado a ser, en toda su extensión (como se expuso supra), una empresa, que, como tal, efectúa operaciones con terceros, para la satisfacción de sus necesidades.

\section{b) Libre adhesion}

No obstante, aun perduraban disposiciones como la derogada Ley de Cooperativas de Euskadi de 1993, que no se referían específicamente a los principios cooperativos formulados por la ACI, lo que sí ha encontrado cabida con la reciente LCPV de 2019, en cuya E.M. justifica esta introducción en el objetivo de alcanzar "una mayor precisión y comprensión” del concepto de cooperativa, "además de una más certera interpretación y aplicación normativa” ajustada a dichos principios. Y, entre esos principios, el de puertas abiertas ha sido positivizado por el nuevo texto legislativo vasco (que se refiere al mismo como principio de "asociación voluntaria y abierta") hasta el punto de que, al igual que la Declaración de la ACI sobre Identidad Cooperativa de 1995, alude a que la aceptación o denegación de la admisión no podrá fundamentarse en motivos que supongan "cualquier tipo de discriminación” en rela-

68. Vid. SANTOS DOMÍNGUEZ, M.A.: “La relación...”, p. 92.

69. Vid. MARÍN HITA, L.: "Reflexiones sobre la creciente mercantilización de las cooperativas al hilo de la nueva Ley de Sociedades Cooperativas de Extremadura”, REVESCO. Revista de Estudios Cooperativos, no 134, 2020, p. 7. DOI: https://dx.doi.org/10.5209/REVE.69167. 
ción con el objeto social. Opción, esta, que se remonta a lo dispuesto por el art. 31.1 LGC de 1987, cuando preceptuaba que, "los estatutos establecerán los requisitos necesarios para la adquisición de la condición de socio, que en ningún caso podrán estar vinculados a motivos políticos, sindicales, religiosos, de nacionalidad, sexo, raza o estado civil, salvo que fueran incompatibles con el objeto social".

Por otra parte, el art. 47.1 LCCV, que ordena el respeto a los principios cooperativos entre los deberes de los administradores, agregando el art. 117.4 a) que se considerará infracción muy grave la "desvirtuación de la cooperativa, cuando se violen de forma reiterada los principios cooperativos reconocidos en esta ley o cuando se admita como socios o socias a personas que legalmente no pueden serlo". De hecho, el art. 20 LCCV, titulado como "derecho a la admisión", al efecto, establece que, “(...) toda persona que reúna los requisitos del artículo anterior (referido a las personas que pueden ser socias) y esté interesada en utilizar los servicios de la cooperativa, tiene derecho a ingresar como socia salvo que lo impida una causa justa derivada de la actividad u objeto social de la cooperativa”. Lo más llamativo de su redacción es la excepción que supone la existencia de una justa causa, restrictiva de la operatividad del principio de puertas abiertas, auténtico límite para el aspirante a socio/a, a pesar del cumplimiento por su parte de los requisitos fijados por el art. 19 de dicha Ley. No obstante, no existe discreción alguna por parte de la cooperativa para este rechazo, por cuanto que la justa causa ha de derivarse de su actividad u objeto social, debiendo tener carácter objetivo, no pudiendo quedar su calificación al arbitrio del Consejo Rector, como puede observarse, v.gr., en la LCCM (art. 19.2), al preceptuar que, "la aceptación o denegación de la admisión no podrá deducirse por causas que supongan una discriminación arbitraria o ilícita”.

Sobre la forma de entender el silencio por parte del Consejo Rector ante la formulación de la solicitud, la actual LCCAT (art. 29.2) supera la anquilosada concepción de dicha omisión que fijaba la previamente vigente Ley catalana de $2002^{70}$, estableciéndose, en la nueva redacción, que, transcurrido el plazo de tres meses ${ }^{71} \sin$ haber sido notificada resolución a la persona interesada, la solicitud ha de ser entenderse estimada, en línea con la solución aprobada por el vigente art. 13 LCOOP, al tiempo que se otorga al Consejo Rector un mayor margen temporal para resolver. La falta de respuesta al interesado también se entiende en el sentido de que se admite al mismo por el art. 18.3 LSCA, al disponer que, “(...) notificado el acuerdo de admisión o transcurrido el citado plazo sin que medie notificación, la persona aspirante a socio o socia contará con un plazo de un mes para suscribir y desembolsar las aporta-

70. Recuérdese que el art. 18.1 disponía que, en caso de que no tuviera respuesta, debía entenderse denegada. 71. Sustitutorio del previgente de dos meses. 
ciones (...)". En la misma línea de estimar el silencio como positivo, véase la LCCV, en su art. 20.2; la Ley 4/2001, de 2 de julio, de Cooperativas de La Rioja ${ }^{72}$ (LCLR), en su art. 21.2; la Ley 1/2003, de Cooperativas de las Illes Balears ${ }^{73}$ (LCIB), en su art. 20.3; la LSCRM, en su art. 23.1; o la LCPV, en su art. 20.3. Sin embargo, otras leyes autonómicas como la LCCANT (art. 18.2), han optado por estimar el silencio como negativo. Ante esta denegación, el solicitante podrá oponer recurso en el plazo de quince días desde la comunicación de la decisión ante el Comité de Recursos ${ }^{74}$, si lo hubiere; o, ante la falta de este (como es el caso de la propia LCCANT, en su art. 29.5; la LCAS, art. 22.2; o la LCCAM, en su art. 26.2), ante la primera asamblea general a celebrar (art. 18.3).

En relación con los plazos de resolución de la solicitud de admisión, no todas las leyes autonómicas han ido en la dirección de ampliar dicho período resolutorio, pues, otras, como la reciente LCPV han transitado en pos de mantener el plazo prefijado por su antecesora, concretado en dos meses (sesenta días, para ser más precisos).

\section{c) Baja voluntaria ${ }^{75}$. Su calificación como justificada o injustificada}

En relación con la baja, en cuanto que pérdida de dicha condición, y como efectiva manifestación del principio de puertas abiertas, en la legislación autonómica, como no podía ser de otra manera, es reconocida por todas las leyes de cooperativas. Por ejemplo, el art. 26 de la novedosa LCPV concede un derecho de salida voluntaria en todo momento, como ya dispusiera su predecesora de 1993, al tiempo que prevé que la pertenencia del socio/a a la cooperativa será por tiempo indefinido, como "doble cara" de una misma moneda. Esto es, de un lado, pertenencia indefinida y, de otro, salida voluntaria de la estructura social en todo momento ${ }^{76}$. En la misma línea, véase la LCG, art.1.1; la LSCRM, art. 30.1; la LCCAT, art. 4 a); o el art. 22 LCAR. No obstante, y a pesar de que el derecho a causar baja mediante preaviso es

72. BOE no 172 , de 19 de julio de 2001.

73. BOE no 91, de 16 de abril de 2003.

74. Denominado Comité Técnico, por su parte, en la LSCA.

75. Debe advertirse que en este análisis se obviará la referencia al otro tipo de baja, esto es, la baja obligatoria, por no derivar, precisamente, del principio de adhesión y baja voluntaria objeto de este ensayo, sino por la pérdida de los requisitos exigidos para ser persona socia según la ley o los estatutos (vid., art. 17.5 LCOOP).

76. Vid. ARRIETA IDIAKEZ, F.J.: La baja como causa de finalización de la relación societaria entre la persona socia y la sociedad cooperativa, Dykinson, Madrid, 2019, p. 30; y GAMINDE EGIA, E.: "Las altas de los/ as socios/as en las sociedades cooperativas", Boletín de la Asociación Internacional de Derecho Cooperativo (BAIDC), no 51, 2017, p. 195. DOI: http://dx.doi.org/10.18543/baidc-51-2017pp191-208 
un derecho característico de las sociedades personalistas y, entre ellas, la sociedad cooperativa, no todas las leyes autonómicas lo explicitan en el catálogo de derechos de la persona socia (entre las que lo citan expresamente, vid., la LSCA, art. 19.1 h); la LCCANT, art. 19.2 f); la LCCLM, art. 35.3 f); o la LCRM, art. 27.2 f)).

La calificación y determinación de los efectos de la baja, debe recordarse, son competencia del Consejo Rector ${ }^{77}$, quien debe comunicárselo a la persona socia interesada por escrito motivado. En este sentido, el art. 17.2 párrafo segundo LCOOP preceptúa, en relación con las consecuencias de eventuales retrasos del Consejo Rector en la atención de las bajas voluntarias de los socios/as, siguiendo lo fundamentado en relación con la resolución de las solicitudes de ingreso, desde la perspectiva opuesta de la salida de los mismos, que, "transcurrido dicho plazo sin haber resuelto el Consejo Rector, el socio podrá considerar su baja como justificada a los efectos de su liquidación y reembolso de aportaciones al capital (...)". Si bien, hay que advertir que no se trata de una presunción iuris et de iure de baja justificada, pues, de una parte, la LCOOP concede una facultad potestativa renunciable; y, de otra, la cooperativa puede tener pruebas de que concurren causas para discutir con la persona socia dicha calificación, así como para impugnarla judicialmente ${ }^{78}$.

Sin embargo, como ya se ha reiterado, el derecho a causar baja no es un derecho absoluto, menos, en un tipo social personalista como la cooperativa, que somete a las personas socias a una particular exigencia de lealtad, incompatible con la baja injustificada y extemporánea, como se desprende de leyes como la LCAS (art. 33), al preceptuar que, “(...) con arreglo a lo previsto en el artículo 92.4, el derecho de baja voluntaria podrá prohibirse estatutariamente, pero el socio siempre ostentará el derecho a transmitir sus aportaciones sociales a otro miembro de la cooperativa o a un tercero de conformidad al régimen previsto legal y estatutariamente para la transmisión del capital social en estos casos"; o la LCCLM (art. 30), que señala que esta interdicción de baja voluntaria deberá tener el respaldo de la mayoría reforzada de "dos tercios de los votos presentes o representados en la asamblea". La ley manchega plasma una salvedad, consistente en que los asistentes a dicha asamblea que hubieren votado en contra del acuerdo prohibitivo de baja voluntaria, siempre que lo acrediten mediante acta o notificación ulterior, y los ausentes que comunicasen su disconformidad en el plazo de cuarenta días mediante escrito dirigido al órga-

77. Sin embargo, la reciente LCPV hace referencia explícita a las "personas administradoras" (art. 26.6), omitiendo la mención al Consejo Rector. En cualquier caso, ambas nomenclaturas han de entenderse equivalentes.

78. Vid. PAZ CANALEJO, N.: "Bajas voluntarias y obligatorias de socios cooperadores en la Ley 27/1999", Revista Vasca de Economía Social, no 0, 2004, p. 40. Handle: http://hdl.handle.net/10810/46673 
no de administración, podrán ejercer su derecho de baja que, en cualquier caso, se entenderá justificada, con el consiguiente derecho al reembolso de las aportaciones obligatorias y voluntarias al capital social que hayan efectuado (art. 51 LCOOP).

En este sentido, se observa que, v.gr., la LCCAT, no ha alterado el régimen existente bajo los parámetros de la Ley de 2002, si bien, se comprueba que en el mismo se concebía como un derecho a la "baja declarada" por el socio/a, en tanto que, en el régimen actual, se trata de un derecho de la persona socia a "solicitar la baja" que será declarada por el Consejo Rector. En cualquier caso, es posible concluir que con la nueva redacción se limita el principio cooperativo de adhesión voluntaria y abierta.

Asimismo, se ha mantenido en algunos textos legislativos, como la misma LCCAT, (art. 31.1); o la LSCA (art. 23.2), la posibilidad de que los estatutos establezcan un tiempo mínimo de permanencia, en la mayoría de los casos, no superior a cinco ańos, similar al compromiso opcional que regula la LCOOP (art. 17.3). Sin duda, este plazo de permanencia se fija en pro de la estabilidad de la sociedad, mitigando su posible "descapitalización", y favoreciendo el aumento de la capacidad de respuesta frente a terceros, y que, al mismo tiempo, se muestra como limitativo de la libertad de la persona cooperativista, demostrando que el derecho a causar baja no se constituye en un derecho absoluto ${ }^{79}$. Idéntico período máximo es establecido por la LCAS, en su art. 31.2; la LCCV, en su art. 22.1; o la LSCRM, en su art. 30.2. También se contempla esta posibilidad en el art. 28.2 LCCM, sin embargo, el límite temporal se fija en seis años. Por su parte, la LCG, en su art. 20.2; o la LFCN, en su art. 23.1, concretan tal plazo en un máximo de diez ańos.

En este sentido, el aspirante deberá advertir que, si los estatutos de la sociedad donde pretende el ingreso incorporan una cláusula de permanencia, su eventual acceso a la sociedad determinará el sometimiento a la misma. De forma contraria, si se produjera la baja de la persona socia infringiendo esta obligación de permanencia, o del compromiso de agotar el ejercicio económico, la misma sería calificada de "injustificada”, con la repercusión económica a que diere lugar, pues, si bien no obstará al percibo del derecho de reembolso, puede reducirse el importe a entregar por la cooperativa, siendo exigible a la persona cooperativista incumplidora una indemnización por los dańos y perjuicios ocasionados (vid., específicamente, art. 51.3 LCOOP, que remite al art. 17.3 del mismo texto legal; y, en la legislación autonómica, v.gr., el art. 22. a) LCAR; el art. 20.2 LCG; el art. 30.2 LSCRM; o el art. 23.2 LSCA in fine, cuando establece que, "el incumplimiento por parte de la persona socia (...) de alguno de los supuestos contemplados en el párrafo anterior, autoriza al órgano de

79. Véase: BORJABAD BELLIDO, J.V., op. cit., p. 164; y MORILLAS JARILLO, M.J. \& FELIÚ REY, M.I., op. cit. 
administración a exigirle la correspondiente indemnización de daños y perjuicios". Entre las normas más recientes, el art. $66 \mathrm{LCPV}$, incorpora como novedad el que los porcentajes de deducción para la baja no justificada puedan incrementarse hasta un máximo de diez puntos porcentuales) ${ }^{80}$.

Particularmente en lo referente a las CTA, el art. 13.4 LCOOP, in fine, faculta a la norma estatutaria para imponer un período de prueba para adquirir la condición de socio/a de trabajo, recalcando el art. 81.3 de dicho texto, que, durante tal período, los nuevos socios tendrán los mismos derechos y obligaciones que los socios trabajadores. Dicho período de prueba se ha mantenido en normas autonómicas recientes como la LCPV, la cual, en su art. 104, fija el límite temporal de seis meses, excepto para unos supuestos concretos, exigentes de unas "especiales condiciones profesionales”, en los que podrá extenderse hasta dieciocho mensualidades. Idéntico paradigma puede observarse en la LSCEX (art. 148), agregando que el número de estos puestos específicos no podrá exceder del $20 \%$ del total de los de la sociedad cooperativa. Diverso plazo para el período de prueba de régimen general es el dispuesto por la LCCV (art. 89.2), determinado en nueve meses (un año para las personas técnicas cualificadas); o en la LCCAT (art. 133), que lo concreta en un máximo de un año, el cual, no resulta aplicable cuando el aspirante pueda demostrar una experiencia como trabajador en dicha cooperativa de al menos un tiempo igual o superior a dicho período de prueba. No obstante, la mayor novedad de este texto legislativo en relación con el período de prueba en las CTA fue la posibilidad de su reducción por mutuo acuerdo, así como que, durante el cual, puede resolverse la relación por decisión unilateral de la persona cooperativista o del Consejo Rector (determinación que, en cualquier caso, ha de comunicarse por escrito), pudiendo optar el primero por recurrir dicho proceder del órgano social, en identidad de términos que los fijados en relación con la denegación de la admisión (art. 29.5 LCCAT).

Se deja al margen de estas consideraciones el derecho de separación de la persona cooperativista, pues, al contrario que la baja voluntaria (que puede tener lugar en cualquier momento mediante el preaviso correspondiente), sólo surge en supuestos determinados, previstos por la Ley (véase, en la LCOOP, el art. 17.4, siguiendo el mismo paradigma que, respecto de las sociedades capitalistas, regula el art. 346 de la Ley de Sociedades de Capital (LSC); y el art. 65, en relación con la fusión de las cooperativas, para aquellas personas socias que no hubieran votado a favor) y los estatutos, en los cuales, el socio/a disidente podrá darse de baja con causa justificada, ante diferentes modificaciones del contrato, en relación con la reestructuración de la empresa. Otros supuestos que pueden acontecer y que, igualmente, se obvia, 
son el que la persona socia sea expulsado de la cooperativa, ante la comisión por su parte de una falta disciplinaria muy grave, tipificada con tal sanción en los estatutos, a consecuencia de la cual, se incoa el correspondiente expediente sancionador (art. 18.5 LCOOP); o que, ante la pérdida de los requisitos para ser socio/a, incurra en baja obligatoria (art. 17.5 LCOOP), concepto específico de las cooperativas ${ }^{81}$. Tanto en el caso de la separación como de la baja obligatoria, o voluntaria injustificada, se plantea si supondrían una vulneración de la prohibición de dejar la validez y el cumplimiento del contrato "al arbitrio de uno de los contratantes" (art. 1.256 CC). Y, en el caso de la expulsión, enmarcada en el ámbito de las normas de disciplina social, si constituiría un supuesto de resolución de obligaciones recíprocas por incumplimiento de uno de los obligados (art. 1.124 CC), atendiendo al cariz mutualista de la cooperativa. No obstante, en lo referente a este supuesto de exclusión, la misma debe observarse en tanto que mecanismo de resolución de conflictos entre las personas socias, y no como una sanción ${ }^{82}$.

\section{Perspectivas de ulteriores reformas en la legislación estatal y autonómica en lo atinente a este principio, en aras de su armonización}

La proliferación de leyes cooperativas, además de contribuir a la desnaturalización y pérdida de los rasgos identitarios del tipo social, de desincentivar su promoción, y de no suplir carencias de la legislación cooperativa estatal, constituye un grave lastre desde el punto de vista de principios como el de adhesión voluntaria, que se vio agravado por el definitivo abandono de la competencia estatal. En consecuencia, es precisa una mayor homogeneidad legal en torno a unos principios básicos para el cumplimiento de los objetivos cooperativos. En efecto, se advierte como imprescindible compatibilizar la adaptación de las cooperativas a las nuevas exigencias empresariales con el mantenimiento de su identidad, amenazada por la profusión legislativa del ordenamiento cooperativo patrio.

Ante el pesimismo de que el status quo legislativo vaya a ser enmendado a corto plazo, hay que posicionarse en favor del establecimiento futuro de un modelo "unipolar" de ley cooperativa, en un esfuerzo colectivo de lealtad que simplifique y racionalice la legislación cooperativa. En definitiva, es precisa una norma única apli-

81. Vid., asimismo, el art. 27 de la nueva LCPV. Por exceder en demasía los objetivos de nuestro trabajo, véase: ARRIETA IDIAKEZ, F.J., op. cit., pp. 43 y ss.; y PAZ CANALEJO, N.: “Bajas...”, pp. 44 y ss.

82. Sobre el particular, in extenso, vid. VIGUERA REVUELTA, R.: El Derecho de reembolso en las sociedades cooperativas, Tirant lo Blanch, València, 2015, pp. 262 y ss. 
cable para situaciones asimilables, sin incurrir en los cuantiosos costes económicos de aprobar tantas leyes que, en la práctica, resultan tan parecidas.

En este sentido, y partiendo del reconocimiento de la competencia exclusiva de las CC.AA. en materia cooperativa, en tanto que conquista histórica a la que no se puede renunciar, el dictado de una ley de armonización por parte del Estado (por virtud del art. 150.3 CE), en aras de la satisfacción del interés general, para aglutinar en un mismo texto legislativo los principios y valores cooperativos en torno a los que la comunidad cooperativa mundial se muestra conforme, llevaría a superar las trabas inherentes a la dispersión normativa actualmente existente ${ }^{83}$. Ley armonizadora cuyo contenido habría de versar únicamente sobre los criterios orientadores para las disposiciones generales y especiales de la cooperativa. Esta armonización se erige en ideal fundamental que debieran convertir en objetivo número uno los diferentes parlamentos, estatal y autonómicos, dando cumplimiento al mandato del art. 129.2 $\mathrm{CE}$ de fomentar, mediante una legislación adecuada, las sociedades cooperativas. Una reforma que, aun manteniendo dichos principios básicos del cooperativismo ${ }^{84}$, haga frente a los desafíos económicos y empresariales por llegar, constituyendo un verdadero marco de flexibilidad donde las cooperativas puedan entrar a autorregularse, dejando atrás el carácter reglamentista que puede dificultar la actividad societaria.

Desde estos parámetros, urge la plasmación legislativa de un acuerdo en torno a principios como el de libre adhesión y baja voluntaria, acabando con la indeseable "subasta" legislativa que ha degenerado en una "pugna" de ordenamientos para captar el mayor número de operadores económicos para la causa cooperativa (el llamado forum shopping ${ }^{85}$ ), y que no es sino consecuencia del palpable vicio de politización que padece nuestra legislación cooperativa. Se comprende que ambos legisladores, estatal y autonómicos, se han apercibido de este defecto, por cuanto que no puede afirmarse que la LCOOP haya cumplido funciones de integración, sino que se ha limitado a ser un texto legal meramente supletorio, por virtud del art. 149.3 CE.

83. Como bien expuso el TC en la Sentencia de 5 de agosto de 1983 (STC no 76/1983; RTC 1983, 76), con motivo de un recurso de inconstitucionalidad contra la primera ley de cooperativas del País Vasco, de 1982.

84. En tanto que la eficacia de los principios y valores cooperativos ha de ser observada más allá del texto legal, hasta el punto de erigirse en verdadera prioridad de la acción de las personas cooperativistas y de las propias entidades. En estos parámetros, vid. GARCÍA JIMÉNEZ, M., op. cit., pp. 6 y ss.; y VICENT CHULIÁ, F.: "El futuro de la legislación cooperativa", CIRIEC-España, Revista Jurídica de Economía Social y Cooperativa, no 13,2002 , pp. 18 y ss.

85. Vid. PANIAGUA ZURERA, M., op. cit.; y PANIAGUA ZURERA, M. \& JIMÉNEZ ESCOBAR, J.: "La necesidad de una legislación cooperativa adecuada: aspectos mercantiles, tributarios y de Derecho comunitario", CIRIEC-España, Revista de Economía Pública, Social y Cooperativa, no 81, 2014, pp. 68 y ss. 
Sin duda, la exigencia de una legislación adecuada obliga a una permanente adecuación legislativa, actualizándose el modo y la intensidad de la actuación administrativa respecto del fomento cooperativo, y sobre el control del cumplimiento de la legalidad cooperativa. Igualmente, para este objetivo se ha de tener en cuenta el estado actual y la evolución de la normativa en materia mercantil en general, junto con los desarrollos y soluciones cooperativas del Derecho comparado.

Sin embargo, de la vigente regulación son aprovechables cuestiones como la formulación del concepto de cooperativa y la referencia expresa a los principios cooperativos formulados por la ACI, que han ayudado a precisar y comprender dicha noción. No obstante, en lo relativo a aspectos como la regulación de operaciones con terceros, debe optarse por el prevalimiento de las transacciones cooperativas con las personas socias, en tanto que diferencia fundamental respecto de las sociedades de capital. Sin obviarse que la propia ACI reconoce que las relaciones con terceros permiten un mejor cumplimiento del principio de adhesión voluntaria y abierta, en tanto que las meritadas actividades con personas no socias pueden ser utilizadas como un elemento facilitador de la incorporación de nuevos asociados, al tiempo que favorece el fortalecimiento empresarial de la cooperativa.

En síntesis, se hace precisa una nueva Ley de cooperativas estatal que termine con el "despropósito" que supone que cada C.A. adopte su propia legislación en una materia de tal relevancia, carente de una mínima homogeneidad, auténtica rémora en el desarrollo del cooperativismo y frontalmente contradictorio con lo ordenado por el art. 129.2 CE. Se aboga, desde esta perspectiva, por superar los particularismos normativos, conducentes única y exclusivamente a la inseguridad jurídica. Este conjunto de leyes debe dar lugar a la conformación de un solo texto legislativo de índole estatal que tenga como eje vertebrador los valores y principios proclamados por la ACI, pero que, al contrario de lo acontecido hasta el momento actual, sea de aplicación a todo el territorio nacional, y no sea un mero recurso residual o en defecto de norma autonómica.

En definitiva, esta ley armonizadora debe establecer un marco institucional idóneo para la constitución y registro de las sociedades cooperativas, tal y como desde la Declaración sobre la Identidad Cooperativa de la ACI, de 1995, se viene defendiendo, que lleve a la paulatina armonización de las legislaciones de todo el mundo, atendiendo a las peculiaridades y situación de cada Estado, a la par que es preciso compatibilizar la adaptación de las cooperativas a los nuevos escenarios del impulso empresarial de los últimos tiempos, debiéndose, de esta manera, adecuar los principios cooperativos, entre ellos, el de libre adhesión y baja voluntaria, a los tiempos futuros. De manera que, las hondas transformaciones habidas y por haber en el cooperativismo no deben dar lugar a un distanciamiento de dichos valores y principios 
tradicionales, que puedan redundar en una merma de su efectividad, al tener que acudir a la concreta disciplina legal aplicable y a la concreta regulación estatutaria de cada sociedad. Todo lo cual, podría traer consigo un impulso al fomento del cooperativismo como forma de ejercer la libertad de empresa en el mercado.

\section{Conclusiones}

La legislación española, en tanto que ordenamiento "plurilegislativo", ofrece un marco respetuoso con el espíritu de los principios cooperativos de la ACI, cumpliendo con la función hermenéutica que les es propia. Por consiguiente, se ha producido su "positivización" en la legislación cooperativa patria, particularmente, en lo referente al principio de puertas abiertas, el cual, quedó reflejado en el precepto inicial de la LCOOP, así como en la mayoría de leyes autonómicas, en tanto que elemento distintivo del cooperativismo respecto de los tipos sociales capitalistas. Y ello, en buena lógica, por cuanto que fuera de los valores y principios cooperativos no hay cooperación ni cooperativas. En cualquier caso, esta asimilación de valores y principios no se ha producido con todo el alcance que se pretendía en los inicios del movimiento cooperativo, puesto que las sucesivas modificaciones legislativas no han supuesto una mejora sustancial.

A pesar de las bondades descritas sobre la sucesión de leyes autonómicas, es incuestionable que la misma dota de inseguridad jurídica a este importante sector del ordenamiento jurídico, lo que manifiesta la necesidad de una regulación armonizada para todo el territorio nacional, por cuanto que dicha amalgama legislativa no supone la introducción de sustanciales novedades normativas que mejoren técnicamente la situación jurídica previa. A este respecto, las continuas reformas en nuestra legislación cooperativa no tienen como objetivo una aplicación más plena de los valores y principios cooperativos, entre ellos el de libre adhesión y baja voluntaria, sino que dicha legislación resulte más atractiva económicamente para las personas socias y empresarios o empresarias cooperativos, habiendo lugar a una auténtica "competición” normativa entre CC.AA. en busca de la legislación más permisiva. Lo que, en cualquier caso, redunda en un límite a la libertad de las cooperativas para competir en los mercados, pudiendo desembocar en una regulación "perversa" de las mismas, dando lugar a que se desvirtúe la identidad cooperativa. Por tanto, si son muchas las ventajas de optar por el modelo social cooperativo, debe potenciarse, en aras de su consolidación en el "turbulento" universo industrial.

En definitiva, hay que sostener que, si el legislador ciertamente se ha fijado como objetivo mantener la mencionada identidad cooperativa, dando cumplimiento a los 
compromisos asumidos nacional e internacionalmente, haciendo peligrar la propia subsistencia de la cooperativa, debe optar por reformar la legislación con el fin de otorgar un marco jurídico apropiado para la cooperativa, diverso al existente para las sociedades de capital. Lo que hallaría satisfacción con el dictado de la reclamada ley de armonización. 


\section{Bibliografía}

ALFONSO SÁNCHEZ, R.: "Los principios cooperativos como principios configuradores de la forma social cooperativa", CIRIEC-España, Revista Jurídica de Economia Social y Cooperativa, no 27, 2015, pp. 49-86.

ALIANZA COOPERATIVA INTERNACIONAL [ACI]: Declaración sobre la Identidad y principios cooperativos, XXXI Congreso de la Alianza Cooperativa Internacional, Manchester, 1995. Recuperado de http://www.ica.coop/coop/principles.html

- Notas de orientación para los principios cooperativos, Bruselas, 2016. Recuperado de https://www.ica.coop/sites/default/files/publication-files/guidance-notes-es-2107251738.pdf

ARCO ÁLVAREZ, J.L. DEL: "Los Principios cooperativos en la 'Ley General de Cooperativas", Estudios cooperativos, no 36-38, 1975-1976, pp. 5-84.

ARRIETA IDIAKEZ, F.J.: La baja como causa de finalización de la relación societaria entre la persona socia y la Sociedad Cooperativa, Dykinson, Madrid, 2019.

BORJABAD BELLIDO, J.V.: "Los principios cooperativos con especial atención al principio de libre admisión y baja voluntaria, su formulación por la A.C.I. y su acogimiento por la legislación española", Anuario de la Fundación Ciudad de Lleida, no 24, 2013, pp. 67-226.

FAJARDO GARCÍA, I.G.: "Novedades en la Ley 27/1999, de 16 de julio, en torno a la constitución y los socios de la cooperativa", REVESCO. Revista de Estudios Cooperativos, no 69, 1999, pp. 81-98.

GADEA SOLER, E.: "Delimitación del concepto de cooperativa: de los principios cooperativos a la responsabilidad social cooperativa”, CIRIEC-España, Revista Jurídica de Economía Social y Cooperativa, no 23, 2012, pp. 37-58.

GADEA SOLER, E., SACRISTÁN BERGIA, F. \& VARGAS VASSEROT, C.: Régimen jurídico de la sociedad cooperativa del siglo XXI: realidad actual y propuestas de reforma, Dykinson, Madrid, 2009.

GAMINDE EGIA, E.: "Las altas de los/as socios/as en las sociedades cooperativas", Boletín de la Asociación Internacional de Derecho cooperativo (BAIDC), no 51, 2017, pp. 191-208. DOI: http://dx.doi.org/10.18543/baidc-51-2017pp191-208 GARCÍA JIMÉNEZ, M.: "La necesaria armonización internacional del Derecho Cooperativo", REVESCO. Revista de Estudios Cooperativos, no 102, 2010, pp. 79-108. 
GARCÍA-GUTIÉRREZ FERNÁNDEZ, C.: "La necesidad de la consideración de la sociedad cooperativa como entidad mercantil para la adecuada legislación", REVESCO. Revista de Estudios Cooperativos, no 66, 1998, pp. 207-234.

HENRŸ, H.: Orientaciones para la legislación cooperativa, Oficina Internacional del Trabajo (OIT), Ginebra, 2013.

JULIÁ IGUAL, J.F. \& GALLEGO SEVILLA, L.P.: "Principios cooperativos y legislación de la sociedad cooperativa española: el camino hacia el fortalecimiento de su carácter empresarial", REVESCO. Revista de Estudios Cooperativos, no 70, 2000, pp. 125-146.

LASSALETTA GARCÍA, P.J.: El acceso a la condición de socio en la sociedad cooperativa de trabajo asociado, Editorial Reus, Madrid, 2011.

LLOBREGAT HURTADO, M.L.: Mutualidad y empresas cooperativas, J.M. Bosch Editor, Barcelona, 2005.

LLUIS Y NAVAS, J.: "La evolución de las directrices fundamentales de la legislación cooperativa española (1931-1975)", Estudios cooperativos, no 39, 1976, pp. 3-40.

MARÍN HITA, L.: "Reflexiones sobre la creciente mercantilización de las cooperativas al hilo de la nueva Ley de Sociedades Cooperativas de Extremadura", REVESCO. Revista de Estudios Cooperativos, no 134, 2020, pp. 61-70.

DOI: https://dx.doi.org/10.5209/REVE.69167

MARTÍNEZ CHARTERINA, A.: "El principio de adhesión voluntaria y abierta desde una perspectiva histórica y doctrinal”, Boletín de la Asociación Internacional de Derecho Cooperativo (BAIDC), no 51, 2017, pp. 179-190.

DOI: http://dx.doi.org/10.18543/baidc-51-2017pp179-190

MIRANDA, J.E. DE: "De la adhesión voluntaria a las puertas abiertas a medias: la arbitrariedad en el cumplimiento de un principio cooperativo", Boletín de la Asociación Internacional de Derecho Cooperativo (BAIDC), no 51, 2017, pp. 63-77. DOI: https://doi.org/10.18543/baidc-51-2017pp63-77

MONZÓN CAMPOS, J.L.: "Las cooperativas de trabajo asociado ante la reforma de los principios cooperativos", REVESCO. Revista de Estudios Cooperativos, $\mathrm{n}^{\circ}$ 61, 1995, pp. 47-52.

MORENO FONTELA, J.L.: "Las relaciones entre los valores y principios cooperativos y los principios de la normativa cooperativa", REVESCO. Revista de Estudios Cooperativos, no 124,2017 , pp. 114-127.

DOI: http://dx.doi.org/10.5209/REVE.54923

MORILLAS JARILLO, M.J. \& FELIÚ REY, M.I.: Curso de Cooperativas, Editorial Tecnos, Madrid, 2019.

PANIAGUA ZURERA, M.: "La sociedad-empresa cooperativa en la evolución de los modelos ius cooperativos en España”, Revista de Derecho de Sociedades (RdS), no 40, 2013, pp. 159-205. 
PANIAGUA ZURERA, M. \& JIMÉNEZ ESCOBAR, J.: "La necesidad de una legislación cooperativa adecuada: aspectos mercantiles, tributarios y de Derecho comunitario", CIRIEC-España, Revista de Economia Pública, Social y Cooperativa, no 81, 2014, pp. 61-93.

PAZ CANALEJO, N.: "Principios cooperativos y prácticas societarias de la cooperación”, REVESCO. Revista de Estudios Cooperativos, no 61, 1995, pp. 15-34.

— "Bajas voluntarias y obligatorias de socios cooperadores en la Ley 27/1999", Revista Vasca de Economía Social, no 0, 2004, pp. 25-57. Handle:

http://hdl.handle.net/10810/46673

PULGAR EZQUERRA, J.: "La pérdida de la condición de socio en el marco cooperativo: Su baja y expulsión”. En: Estudios de Derecho Mercantil. En memoria del Profesor Aníbal Sánchez Andrés (coords. SÁENZ GARCÍA DE ALBIZU, J.C., OLEO BANET, F. \& MARTÍNEZ FLÓREZ, A.), Civitas, Pamplona, 2010, pp. 1.039-1.082.

SANTOS DOMÍNGUEZ, M.A.: El poder de decisión del socio en las sociedades cooperativas: la Asamblea General, Aranzadi, Cizur Menor (Navarra), 2014.

— "La relación de los principios cooperativos con el Derecho", CIRIEC-España, Revista Jurídica de Economía Social y Cooperativa, no 27, 2015, pp. 87-132.

SERRANO Y SOLDEVILLA, A.D.: La cooperativa como sociedad abierta, Ministerio de Trabajo y Seguridad Social, Servicio de Publicaciones, Sevilla, 1982.

TRUJILLO DÍEZ, I.J.: "El valor jurídico de los principios cooperativos. A propósito de la Ley 27/1999, de 16 de julio, de cooperativas", Revista Critica de Derecho Inmobiliario, no 658, 2000, pp. 1.329-1.360.

VARGAS VASSEROT, C.: "El principio cooperativo de puertas abiertas (adhesión voluntaria y abierta). Tópico o realidad en la legislación y en la práctica societaria”, CIRIEC-España, Revista Jurídica de Economía Social y Cooperativa, no 27, 2015, pp. 133-174.

- "El nuevo (por diferente) marco legal de las sociedades cooperativas en Andalucía. El paso de una concepción social de la cooperativa a una economicista radical", Revista de Derecho de Sociedades (RdS), no 53, 2018.

VICENT CHULIÁ, F.: "El futuro de la legislación cooperativa", CIRIEC-España, Revista Jurídica de Economía Social y Cooperativa, no 13, 2002, pp. 9-48.

— "Introducción. Normas y ámbito de aplicación". En: Tratado de Derecho de sociedades cooperativas (dir. PEINADO GRACIA, J.I. \& coord. VÁZQUEZ RUANO, T.), Tirant lo Blanch, València, 2019, pp. 57-110.

VIGUERA REVUELTA, R.: El Derecho de reembolso en las sociedades cooperativas, Tirant lo Blanch, València, 2015. 